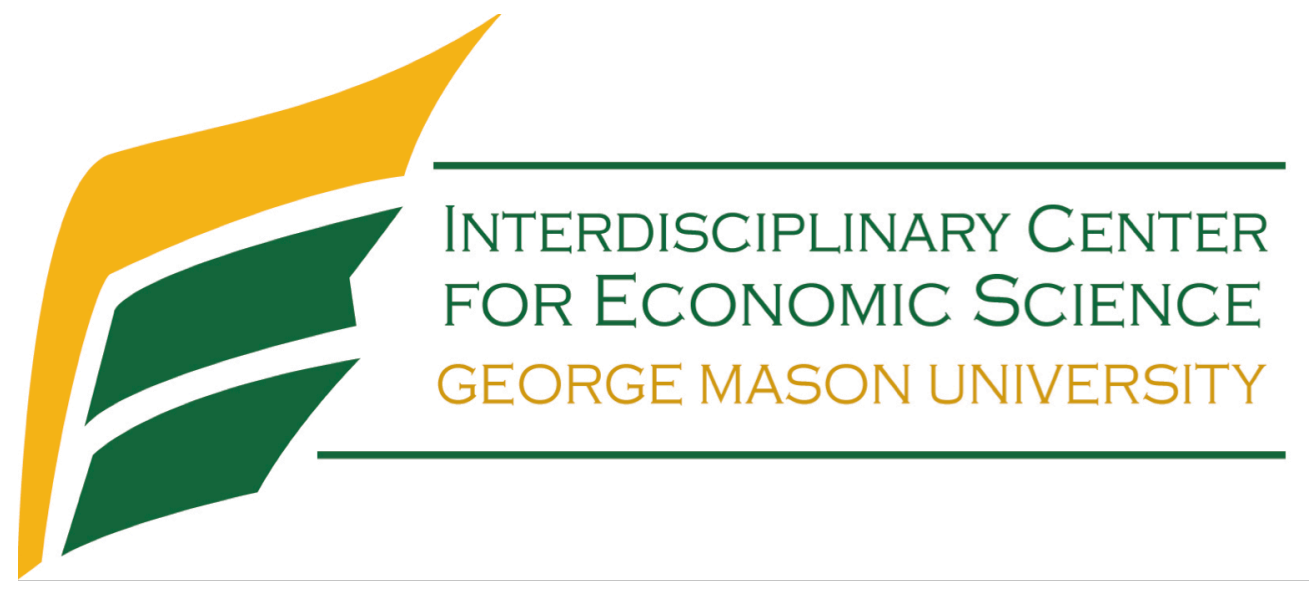

\title{
Growing Stars: A Laboratory Analysis of Network Formation
}

\author{
Rong Rong and Daniel Houser
}

September 2012

Discussion Paper

Interdisciplinary Center for Economic Science

4400 University Drive, MSN 1B2, Fairfax, VA 22030

Tel: +1-703-993-4719 Fax:+1-703-993-4851

ICES Website: $h$ ttp://ices.gmu.edu

ICES RePEc Archive Online at: http://edirc.repec.org/data/icgmuus.html 


\title{
Growing Stars: A Laboratory Analysis of Network Formation
}

\begin{abstract}
The acquisition and dispersion of information, a critical aspect of economic decisions, can occur through a network of agents (Jackson, 2009). Empirical and theoretical findings suggest that an efficient information dispersion network takes the form of a star: small numbers of agents gather information and distribute it to a large group. Controlled tests of this theory, however, have typically found little evidence of star network emergence. An exception is Goeree et al (2009), which reports reliable star network formation in an environment that includes ex ante heterogeneous agents. While heterogeneity may explain network formation sometimes, it seems to play a smaller role in other cases (Feick and Price, 1987; Conley and Udry, 2010). In this paper we investigate whether specific institutional conditions promote star network formation with ex ante homogeneous agents. We find that investment limits and the "right-offirst-refusal," both of which are institutions that stabilize decision making, have a surprising ability to promote star network formation. Further, using a cluster analysis that allows us to draw inferences about individuals' behavioral rules, we find that these effective institutions encourage individual rationality as well as positive habits. We argue that these decision rules emerge due to the stabilizing features of the institutions and this stability facilitates improved network behaviors and outcomes.
\end{abstract}

JEL classification: D85, D02, C92

Keywords: Social networks, star network formation, cluster analysis, experiments 


\section{Introduction}

How information is initially acquired and subsequently dispersed among people is widely studied in economics (Rogers, 1995). In many relevant contexts, it occurs through networks of agents (Jackson, 2009). Empirical and theoretical findings suggest that efficient information networks take the form of a star: small numbers of agents gather information and then distribute it to a larger group (Weimann, 1994; Bala and Goyal, 2000; Galeotti and Goyal, 2010). Despite the theoretical advances, one persistent challenge has been discovering the conditions under which star networks emerge within controlled laboratory environments. One way to reliably generate star networks is to incorporate ex ante agent heterogeneity (Goeree, et al, 2009). Although this condition explain the formation of star networks in many cases, it is possible they will be less important in other naturally occurring network environments (Feick and Price, 1987; Conley and Udry, 2010). Our paper addresses the question of whether specific naturally occurring institutions, and particularly those that work to add stability to the network environment, may promote star network emergence in the presence of homogeneous agents.

The earliest works on star networks date back to the 1950s. In their pioneering paper, Katz and Lazersfeld (1955) coined the term "opinion leaders" to describe a small subset of highly connected people ${ }^{1}$. Half a century later, studies continue to provide empirical support for the existence of opinion leaders in politics and marketing (Weimann, 1994; Katz and Lazersfeld, 2006). Opinion leaders clearly make a difference. For instance, empirical evidence has shown that words from opinion leaders boost sales of consumer products (Godes and Mayzlin, 2009), contribute to the prevention of AIDS (Kelly et al, 1992), and transmit political thought and ideas (Roch, 2007). Given importance of the opinion leaders in disseminating information, people in both the private and public sectors are eager to discover how to locate and influence the star center (Iyengar et al, 2008). A deeper understanding of the emergence and characteristics of star networks, a stylized opinion leader network, could help to facilitate such efforts.

\footnotetext{
For helpful comments we thank Jacob Goeree, Charles Plott, Arno Riedl, Aljez Ule, Tyler Cowen, Carlos Ramirez, OmarAl-Ubaydli, Fangfang Tan, Boris van Leeuwen and our colleagues at ICES, George Mason University, seminar participants at Workshop on Experiments and Econometrics at Berlin (2011), the ESA international meeting (2012), University of Arkansas (2012), Higher School of Economics, Moscow (2012) and Stanford Institute of Theoretical Economics workshop (Segment 5, 2012). We are grateful to the Interdisciplinary Center for Economic Science (ICES) for funding this research. The authors are of course responsible for any errors in this paper.

${ }^{1}$ The concept of "influentials" can largely be used interchangeably (Merton, 1968; Gladwell, 2000).
} 
Research on star networks connects to the empirical literature on so-called scale-free networks. Loosely speaking, a network is denoted as scale-free when the majority of nodes have only a small number of links, and a small minority of nodes have a very large number of links. For example, collaboration networks are scale free. The distribution of both the number of citations a paper receives and the number of coauthors a researcher has tends to follow a power law distribution; indicating that a small number of papers and researchers play a central role in the scientific world. Another example is Internet Pagerank networks. These networks are scalefree in the sense that a small number of web pages have a disproportionately high likelihood of being mentioned by other pages. Yet another example is Twitter: most twitter users obtain information from a very small number of people in their network. ${ }^{2}$ Star networks are scale-free networks. Understanding how star networks emerge in the laboratory can inform the growth, efficiency and stability of scale-free networks in natural environments.

Theoretical studies of star networks have shown that under certain conditions, star networks emerge endogenously and include efficient and stable equilibria (Bala and Goyal, 2000; Galeotti and Goyal, $2010^{3}$ ). Certain crucial conditions underlie the formation of equilibrium star networks, namely that: (1) information can be shared (meaning it is non-rival); and (2) agents are able to form links unilaterally ${ }^{4}$. While strong, these conditions are easily implementable in laboratory tests and are attractive in that many environments where information dispersion is important are characterized by these conditions ${ }^{5}$.

To investigate star-network formation, economists have begun to collect laboratory data from participants in various network environments (Callander and Plott, 2005; Falk and Kosfeld, 2003; Goeree et al, 2009). Loosely speaking, in a typical network formation experiment, players decide how to form "links" with other players in light of the benefits those links confer. These studies have not always, however, succeeded in discovering star networks ${ }^{6}$. To our knowledge,

\footnotetext{
${ }^{2}$ Detailed examples of scale-free networks could be found at (Barabasi, 2004).

${ }^{3}$ Some non-game-theoretical models of star network formation build upon preferential attachment and study the behavior of large networks (Barabasi and Albert, 1999; Jackson and Rogers, 2007). A direct test of those models needs validation of its behavioral assumptions, which is difficult to achieve with a lab experiment.

${ }^{4}$ Jackson and Wolinsky (1996) discussed two cases in which those two conditions are lacking. They found that network efficiency and stability is hard to achieve under regular payoff functions.

${ }^{5}$ Knowledge generated in academia is one example. Open source software is another example. This excludes cases where information is protected by IPR and dispersion of that information requires bilateral agreements such as those found in some enforceable contracts.

${ }^{6}$ Falk and Kosfeld (2010) found equilibrium "wheel" networks to emerge, but were not able to observe the formation of equilibrium star networks.
} 
the single exception is Goeree et al (2009), which finds star networks to emerge reliably in the presence of ex ante agent heterogeneity. The authors argue that this heterogeneity promoted star networks by simplifying the network coordination problem.

Ex ante heterogeneity may help to explain the emergence of networks in many environments (e.g., co-authorship), but may not be the entire solution in other naturally occurring network environments (Feick and Price, 1987; Conley and Udry, 2010). Consequently, here we investigate network formation in the presence of ex ante homogeneous agents. In particular, we study whether certain naturally-occurring institutional features may promote star-network formation.

We study institutions that we expect to add temporal "stability" to decisions, in the sense of reducing period-to-period changes in the decisions people make. Agent heterogeneity plays this role, in that people who have an advantage in investing or linking may be more likely to so repeatedly, and others may be more able to form accurate expectations about their play. As we argue below, institutions can also play this role, and in doing so promote the emergence of star networks even in the absence of heterogeneity or other sorts of focal points.

We collect data from laboratory experiments to examine whether efficient star network formation can be promoted by adding stability to the environment with the following institutions: (1) sequential decisions; (2) investment limits (effectively, budget constraints); and (3) "right of first refusal," which ensures that investors are able, should they desire to do so, to continue their investments.

Each of the institutions we investigate may stabilize people's decisions in networks. This may explain why these institutions seem connected to the emergence of naturally occurring networks. For example, online networking sites, such as Facebook or Twitter, regularly ask current users to invite their friends to join the site, and then those friends ask their friends. We incorporate sequential decisions into our experiment design.

Investment limits are a regular feature of natural network environments, as (1) technologies are too expensive to allow repeated R\&D investment (Dimasi et al, 2003; Dimasi and Grabowski, 2007) and (2) government policies exist to prevent wasteful repeated investments (Tran, 2009). Moreover, when personal relationships are at stake, information investment may face natural constraints with regard to time or distance (Marsden and Campbell, 1984). In this paper, investment limits are modeled as a type of individual budget constraints. 
The "right of first refusal" (which we denote by RFR) is a business contract where the privilege of investment is granted to an investor who has invested in the immediate past. Aside from being a common business practice, RFR emerges regularly whenever economic outcomes favor persistent investments on one agent rather than the spreading of resources across multiple smaller investments, which is of course a characteristic of star networks. Take, for instance, the situation in which low income families in developing countries decide which child to send to school; firms choosing which employees to give additional training; or funding agencies selecting which scholars' projects to fund. In each of these cases, the predictability of the investor's identity serves as the coordination device that may facilitate star network formation. Our experiment design allows us to vary the existence of RFR and measure its impact on network stability and star network formation.

The key finding of our paper is that star networks can reliably emerge with ex ante homogeneous agents. As noted above, this complements previous findings by Goeree et al (2009) and helps to explain the emergence of star networks in natural environment where agent heterogeneity may play a smaller role. In particular, we find that combining investment limits with RFR generates robust star networks, and that these networks are "stable" in the sense that they tend rapidly to reemerge after falling into disequilibrium. The effect persists in either simultaneous or sequential decision environments. Moreover, investment limits alone generate about half of the equilibrium outcomes compared to when they are combined with the RFR. Surprisingly, sequential decision alone does not seem to promote equilibrium networks.

We also examine individual decision rules using cluster analysis and find that the behavior of our lab subjects separates into clearly defined behavioral clusters. We then investigate how different institutions may shift subjects into different types of behavioral rules. Our analysis demonstrates that investment limits in simultaneous decision environments promote the formation of positive habits, which translate into more frequent coordination in star networks. Investment limits in sequential environments generate frequent star networks, largely due to the fact that agents are more likely to follow the rule of rationality predicted by the theory.

Our investigation provides both methodological and substantive contributions. Methodologically, we use cluster analysis to distinguish different behavioral rules used by subjects. These differences help to explain why different institutions lead to different levels of star network formation. To our knowledge, we are the first to implement cluster analysis to shed 
light on the behavioral rules used in social networks, and the first to explain institutional impacts in social network formation environments using these behavioral rules.

Substantively, the findings of our paper have direct implications for information dispersion, which is especially relevant to, e.g., the technology and agricultural sector. Our results suggest that: (1) difficulties with coordination may lead to undesirable network outcomes; and (2) institutional features that promote sustained investment by a single individual facilitate the formation of efficient networks.

The remainder of the paper is organized as follows: The next section briefly reviews the theoretical and experimental literature on network formation. Section 3 lays out the theoretical background of the study. Section 4 presents the experimental design and procedure, and sets up the hypothesis. Section 5 reports experimental results. Section 6 discusses cluster analysis. Section 7 concludes.

\section{Literature Review}

\section{II.1 Theoretical work on star network formation}

Many theoretical studies have attempted to shed light on the process of network formation in general (Jackson, 2003), and recently specific theoretical progress has been made on understanding the conditions under which star networks can form (Bala and Goyal, 2000; Bramoulle et al, 2004; Galeotti and Goyal, 2010). For all the cases that we study in this paper, equilibrium star networks are also efficient. Star networks feature asymmetry in equilibrium actions by participants, because it pays to send links when others invest and vise versa. Note that this environment is characterized by "strategic substitutes", and includes in general both anticoordination games and games related to public goods provision ${ }^{7}$.

An early paper by Bala and Goyal (2000) studied an environment with non-rival network goods and the possibility of forming links unilaterally. They found that star networks emerge in equilibrium only when the benefit of information flows between two agents regardless of who sends the link ${ }^{8}$. Their study was followed by Bramoulle et al (2004), who examined network formation in an anti-coordination game. They found that the shape of the equilibrium network

\footnotetext{
${ }^{7}$ Bramoulle and Kranton (2007) discussed public goods provision in network settings extensively. However, networks in their study are exogenous.

${ }^{8}$ In their model, if only the link sender receives information from the link receiver, the equilibrium network is a wheel.
} 
need not be a star; with the exact network shape depending on the cost of link formation. More recently, a study by Galeotti and Goyal (2010) extended the model of Bala and Goyal (2000) by endogenizing the choice to invest. Their study showed that star networks emerge in equilibrium as well ${ }^{9}$. These advances of course leave open the question of whether the conditions required by theory are sufficient to generate star networks reliably in a controlled laboratory environment.

We now turn to a detailed review of the empirical studies of network formation in the laboratory.

\section{II.2 Experiments on star network formation}

Despite the abundance of empirical evidence related to star networks ${ }^{10}$, we are aware of only four experimental studies on star network formation (Callander and Plott, 2005; Falk and Kosfeld, 2003; Berninghaus et al, 2007; Goeree et al, 2009 ${ }^{11}$ ). Falk and Kosfeld (2003) tested the theory of Bala and Goyal (2000). In particular, they studied whether and how equilibrium networks can form under "one-way" and "two-way" information flows. In contrast with theoretical predictions, they found that when information flows two ways the network fails to converge to a star. They concluded that the need for asymmetric strategies combined with inequality aversion might contribute to the difficulty in realizing star networks.

Callander and Plott (2005) also tested Bala and Goyal (2000) in the lab. They considered various conditions that differed in terms of the linking cost, as well as the value of information. They also examined the impact of having network agents with heterogeneous payoff structure, an issue unaddressed by the model. Their main finding was that star networks did not consistently emerge under theoretical conditions, and that even introducing payoff heterogeneity did not lead to systematic formation of star networks. Consequently, they report that "significant and persistent inefficiency" is a feature of all of their network environments.

Berninghaus et al (2007) provided yet another test of Bala and Goyal (2000) but focused on the comparison between discrete and continuous time environments. In the discrete environments, their results show that players have a tendency to reduce network distance over

\footnotetext{
${ }^{9}$ Galeotti and Goyal (2010) predicts peripheral-sponsored stars, while center-sponsored stars are predicted in the decay free model of Bala and Goyal (2000) and Bramoulle et at (2004).

${ }^{10}$ See Katz and Lazarsfeld (1955), Rogers (1995), Valente (1995)

${ }^{11}$ Experimental studies on endogeneous networks other than star networks include Deck and Johnson (2004), Ule (2005), Corbae \& Duffy (2008), Knigge \& Buskens (2010), Berninghaus et al (2011).
} 
time. However, the overall average frequency of star networks found in their data $(11.33 \%)$ is no greater than what we report below in our baseline environment. ${ }^{12}$

In light of the complications with generating star networks, and following Callander and Plott (2005), Goeree et al (2009) explored whether common knowledge of agent heterogeneity combined with two-way information flows might promote star networks. They reported that: (1) compared to homogeneous agent treatments, significantly more stars are observed when agents' payoffs are heterogeneous ${ }^{13}$; and (2) perfect information about the nature of heterogeneity plays an important role in facilitating the coordination on star networks.

Like the above studies, we explore what conditions may facilitate the emergence of star networks. But in contrast, our study emphasizes the importance of homogeneous agent assumption and explores how institutional characteristics may impact network formation in presence of agent homogeneity.

While Callander and Plott (2005) and Goeree et al (2009) demonstrated the importance of individual heterogeneity in network environments, there may be some environments where individual differences play a smaller role. For instance, information about heterogeneity may not always be easily available in natural environments, due to the fact that it goes unobserved. Indeed, substantial empirical research on market mavens has found no differences between the observable characteristics of agents who play different roles in the network (Feick and Price, 1987; Geissler and Edison, 2005; Wiedman et al, 2001; Williams and Slama, 1995). Others have pointed out that obtaining information about the costs and benefits of other network agents in agricultural environment may be difficult, given that people have an incentive to conceal their private information (Conley and Udry, 2010). Moreover, ex ante agent heterogeneity is not required by theory for star network emergence ${ }^{14}$.

In view of the fact that individual-level information is costly and sometimes infeasible to obtain, and to avoid introducing artificial focal points, we design our experiments to include ex

\footnotetext{
${ }^{12}$ Due to the design of the continuous environments in their study as well as Berninghaus et al (2006), the results could not be easily compared with data from discrete environments. In this study, we focus on discrete environments.

${ }^{13}$ According to their experimental data, the heterogeneity on cost of linking does not seem to significantly promote star network formation.

${ }^{14}$ Jackson and Lopez-Pintado (2011), Larrosa and Tahme (2011), and Vandenbossche and Demuynck (2010), developed models with heterogeneous agents. However, none of these relate to incentives associated with information acquisition or diffusion; therefore, the predictions generated from those models are not star-shaped networks. Galeotti et al (2006) developed models showing that star networks are an equilibrium in environments where agents have heterogeneous benefits for information, while under heterogeneous costs stars are no longer equilibrium.
} 
ante homogeneity. We investigate conditions under which ex ante identical agents will take asymmetric equilibrium actions to establish efficient and stable star networks.

\section{Theoretical Background}

Our study is based on the model of network game in Galeotti and Goyal (2010). In their model, a group of identical rational agents face the choice of either investing in information or obtaining it less expensively by linking to another who currently invested in information. The level of investment by agent $i$ is discrete $x_{i} \in\{0,1\}$. The set of links sent by agent $i$ is denoted by a vector $g_{i}=\left(g_{i 1}, \ldots, g_{i i-1}, g_{i i+1}, \ldots, g_{i n}\right)$, where $g_{i j}=1$ if player $i$ sent a link to player $j$. Linking choices are then combined to determine the directed network structure $g=\left(g_{1}, g_{2}, \ldots, g_{n}\right)^{15}$. The key assumptions of the model are that information is non-rival and flows both ways across network links. ${ }^{16}$

The non-directed version of the network is denoted by $\bar{g}$, where $\bar{g}_{i j}=\max \left\{g_{i j}, g_{j i}\right\}$ for each agent $i$ and $j$. Define $N(i ; g)=\left\{j: g_{i j}=1\right\}$ as the set of agents to whom $i$ has sent a link and $N(i ; \bar{g})=\left\{j: \bar{g}_{i j}=1\right\}$ as a set of agents with whom $i$ has been connected. The payoff to agent $i$ is

$$
\pi_{i}\left(x_{i}, g_{i}\right)=f\left(x_{i}+\sum_{j \in N(i ; \bar{g})} x_{j}\right)-c x_{i}-|N(i ; g)| k
$$

where $c>0$ reflects the cost of investing, $k>0$ is the cost of sending one link and $|N(i ; g)|$ refers to the cardinality of the set $N(i ; g)$.

Different specifications for $f$ define different types of games. In this paper, we follow Galeotti and Goyal (2010) and assume $f$ is a step function

$$
\begin{cases}f\left(y_{i}\right)=1 & \text { if } y_{i} \geq 1 \\ f\left(y_{i}\right)=0 & \text { if } y_{i}<1\end{cases}
$$

where $y_{i}=x_{i}+\sum_{j \in N(i ; \bar{g})} x_{j}$. The above return function $f\left(y_{i}\right)$ resembles the payoff structure of best shot game in the widely studied public good games literature. The advantage to using a step

\footnotetext{
${ }^{15}$ A directed graph is a graph where the edges have a direction associated with them.

${ }^{16}$ These assumptions are important due to the fact that they closely characterize certain situations of information dispersion in natural environments. For example, knowledge about agricultural technology is mostly non-rival, and could be shared between personal connections of farmers regardless of the linking direction.
} 
function is that it provides sharp equilibrium predictions that can be more easily tested in the laboratory ${ }^{17}$.

It can be shown that every equilibrium of the network best shot game is a star network when $k<c$ (Galeotti and Goyal, 2010) ${ }^{18}$. The intuition is as follows: if in equilibrium the sole investor deviates and does not invest, then the group obtains no information, implying a lower payoff for everyone including the investor. Similarly, if a person who has linked to the investor deviates by not linking, choosing to link to another (who in equilibrium cannot have the information), or becoming an investor oneself, then in all cases such deviations clearly lead to lower payoffs. Therefore, the star network is a Nash equilibrium. Note also that all star network equilibria in the best shot game are efficient (in the sense that equilibria are not Pareto ranked). This feature of the network best shot game, as well as its clean equilibrium predictions, leaves it ideal for laboratory testing. In the following section we detail our design, which follows the network best shot game closely.

\section{Experiment design and hypothesis}

Our experiment is designed to examine how naturally-occurring institutions affect star network formation with ex ante homogenous agents. Institutional characteristics such as sequential decisions, investment limits and the RFR often coexist with star networks. We conjecture that these institutional characteristics may be important conditions for the formation of star networks in naturally occurring environments. Our laboratory study brings these institutional features into a controlled laboratory setting and examines the effect of each on star network formation.

\section{IV.1 Experiment Design}

\section{IV.1.1. General Environment}

Our experiment design is based on the best shot game introduced in the appendix of Galeotti and Goyal (2010) ${ }^{19}$. This modification leads to the sharp prediction that a star network is

\footnotetext{
17 Instead of star network, the general model prediction a so-called core-peripheral network, where a few interconnected agents invest in information while the rest of agents connects to them. A star network is a special core-peripheral network that includes a single agent in the core.

${ }^{18}$ When $k>c$, the unique equilibrium is an empty network.

${ }^{19}$ This environment reflect in some ways a job contact network where people turn to other people to obtain information on job opening.
} 
the unique Nash equilibrium configuration (of course there are four such networks that share this same configuration), and is also efficient ${ }^{20}$. To the best of our knowledge, our study is the first to examine the network formation process where agents make simultaneous linking and information investing decisions.

Each experimental session includes 16 subjects randomly divided into four groups. All subjects participate in three stage games. Each stage game consists of a random number of rounds ${ }^{21}$. Groups are fixed during each stage game, and each group member holds a unique ID: J,K,L or M. We avoid using "A" as an ID because it may be focal ${ }^{22}$.

In each round, decision-makers decide to whom to link among their other three group members and also whether to purchase information. Table 1 details the costs and benefits associated with each action a player can take. If a participant purchases information, she pays a cost of E\$0.9 and earns the value of information, E\$3, with certainty. On the other hand, if a player decides to send a link to another player, she pays a cost of E\$0.5 per link. When one subject links to another subject who has purchased information, the subject who chooses to link also earns E\$3. Subjects who link to other subjects that have not purchased the information pay a cost of $E \$ 0.5$, but earn nothing. Costs and payoffs remain fixed throughout all three stage games and all treatments. ${ }^{23}$.

Table 1. Costs and benefits associated with player's actions

\begin{tabular}{|c|c|}
\hline & Parameter value \\
\hline Cost of sending link & $\mathrm{E} \$ 0.5$ \\
\hline Cost of investing in information & $\mathrm{E} \$ 0.9$ \\
\hline Value of information & $\mathrm{E} \$ 3$ \\
\hline Number of player in a group & 4 \\
\hline
\end{tabular}

\footnotetext{
${ }^{20}$ In this earlier version of the paper, Galeotti and Goyal (2007) described a best-shot game where the investment decision is binary. An agent could choose either to invest in one unit or no units of the information . The optimal level of investment for a group is also set to be one, so that any additional investment is inefficient.

${ }^{21}$ There are always at least 4 rounds in a stage. After round 4, the game has a random stopping probability of 0.04 at any given round. To keep control over the length of the real experiment, we use the predetermined length 16,44 and 24 for experimental stages I, II and III respectively. Those numbers are generated using a random number device. The practice stage always lasts for 8 rounds.

${ }^{22}$ Some have suggested that the first mover $\mathrm{J}$ might also be in a focal position. It turns out that, for all treatments, $\mathrm{J}$ is not statistically more likely to be the center of the star than any of the other positions ( $\mathrm{p}>0.195$ in all bivariate comparisons across all treatments, two-sided Mann-Whitney tests)

${ }^{23}$ We choose these parameters to ensure that the predicted equilibrium and efficient networks are star-shaped.
} 
Subjects submit their decisions using the decision screen (see Appendix A, Fig. 1). Then, a display screen informs all players of the current network outcome and each group member's payoff (see Appendix A, Fig.2).

Within each of the three stage games, the payoff is determined by the accumulated earnings over all rounds. Players are informed about their own stage payoff at the end of each stage. They are also reminded that they will be re-matched with players with whom they have not played previously, and that their stage payoff will not be carried over to the new stage. Each subject's earnings for the experiment are determined by one randomly-determined stage game (each with equal probability).

\section{IV.1.2 Treatment Design}

Within the general experimental environment described above, we study the effects of three institutional characteristics of network formation. We examine sequential decisions and investment limits on network formation, both individually and jointly, using a two-by-two treatment design. A fifth treatment then studies the effect of the "right of first refusal."

In a two-by-two design, we vary the sequence of decisions in one dimension to be either sequential or simultaneous. In simultaneous treatments, subjects from the same group make their decisions at the same time, not knowing what other subjects would choose. In sequential treatments, only one subject makes a decision per round. Players make decisions according to the alphabetical order of their ID (first J, then K, L and finally M) with full knowledge of the choices made by earlier decision makers. Further, players earn money even on rounds for which they do not make a decision, with their payoff determined by their most recent previous choice in combination with the choices of others ${ }^{24}$.

The second dimension of our design varies the existence of investment limits. Absent investment limits, players can invest in information and links at will, independently of other players' decisions. On the other hand, in treatments with investment limits, the following three conditions hold: (i) in each round, each player can either send a link or invest in information, but cannot do both; (ii) each player can send at most one link; and (iii) at most one player can invest in information at any given time. We refer to the treatment without limits as the "baseline" in

\footnotetext{
${ }^{24}$ Note that in relation to the simultaneous game, participants make fewer decisions in the sequential game. We made this decision in order to ensure that payoff incentives would be identical between the simultaneous and sequential games.
} 
both the sequential and simultaneous environments, and denote treatments with investment limits as "limits."

Notice that Seq_L and Seq_B differ in two ways: while investment is limited in Seq_L, it also implies the RFR, by which we mean that a person who currently invested in information has the right to continue his/her investment. The reason is that in Seq_L, a subject who has invested in information will continue to hold it until their next decision, and nobody else will be able to invest in additional information. Consequently, the only way they can lose the information is if they give up the information. It follows that comparing Seq_L to Seq_B measures the total effect of the investment limits combined with the RFR.

While these two effects cannot be separated in our sequential environment, it is possible to achieve separation in a simultaneous setting. To do this, we construct a fifth treatment that builds on Sim_L but eliminates the RFR. In any given round, agents who choose to invest in information will have an equal chance to obtain the information, regardless of whether he/she invested the information in the previous round ${ }^{25}$. This treatment is denoted as simultaneouslimits with no RFR (Sim_L_NoRFR).

In summary, we investigate network formation in five treatments that differ in terms of the sequence of moves, whether investment is limited, and the existence or nonexistence of an RFR. We list the properties of these five treatments in Table 2.

Table 2. Properties of Treatments

\begin{tabular}{|c|c|c|c|}
\hline Treatment & Decision sequence & Investment limits? & RFR? \\
\hline Seq_B & Sequential & N & N \\
\hline Seq_L & Sequential & Y & Y \\
\hline Sim_B & Simultaneous & N & Y \\
\hline Sim_L & Simultaneous & Y & N \\
\hline Sim_L_NoRFR & Simultaneous & Y & \\
\hline
\end{tabular}

\section{IV.2. Explanation of Treatment Design}

We select our treatment conditions based on two criteria: (1) the institutions could plausibly provide stability to the network decision environment, and (2) they might bear relevance to the way star networks emerge in natural settings.

\footnotetext{
${ }^{25}$ In Sim_L, if a previous investor chooses to invest, he/she will be able to continue the investment with $100 \%$ certainty. The first period investor is randomly determined if there are multiple players choosing to invest.
} 


\section{- Why sequential decisions?}

It is very common to create networks through a process of sequential decisions. For example, online networking sites, such as Facebook or Twitter, regularly ask current users to invite their friends to join the site, and then those friends ask their friends. Similarly, given that it is infeasible to achieve face-to-face interaction with large numbers of people at the same time and location, social connections that exist "off-line" also generally occur through a sequential process. For example, when farmers consult others before adopting certain new seeds, it is likely that they observe what other farmers have done and turn to the ones that have experimented and gathered experience with the seeds (Foster and Rozensweig, 1995; Conley and Udry, 2010). When decisions made by earlier movers are known to the later movers, sequential environments clearly reduce uncertainty about others' choices. This adds stability to the decision environment, which may promote equilibrium network formation.

\section{- Why investment limits?}

Investment limits are a regular feature of natural environments, and can take two forms. One is a limit on repeated investments in information. These limits emerge because technologies are expensive to create (Dimasi et al, 1991; Dimasi and Grabowski, 2007), often leaving it difficult for multiple groups to obtain the capital necessary to invest in the same idea. Further, policies may exist to prevent inefficient investment in information. For example, to reduce inefficiency caused by excessive rent seeking, many governments choose to limit investment by monopolizing “insider” information (Tran, 2009).

The second form of investment limit arises because creating multiple links may be infeasible. A reason is non-monetary constraints in terms of time or social distance. This can become especially significant in the context of personal relationships, where time spent together is an important factor and often a binding constraint (Marsden and Campbell, 1984). It is plausible that efficient star networks might emerge naturally in the presence of investment limits as a response to limited resources.

Intuitively, reducing the action space may add stability to the decision environment. This is clear in the case of very severe limits (say, when only equilibrium decisions are possible). More generally, by reducing the choice set one may reduce "noise" associated with errors and other sorts of non-optimal decision making. Such effects may add consistency to decisions and, 
consequently, stability to the economic environment. We pursue this possibility in our experiments by designing treatments with investment limits.

The specific limits we consider reduce the set of actions each player can choose, thus reducing the number of possible network outcomes in our experiment ${ }^{26}$. Note that these limits are respected in any equilibrium, though they are not sufficient for equilibrium. Indeed, after imposing these restrictions, there remain 521 unique network outcomes, of which only four are equilibrium.

\section{- Why the "right of first refusal"?}

The right-of-first-refusal (RFR) is a contractual arrangement that often exists between long term trading partners. Its value lies in stabilizing the buying or selling decisions in business relationships. Although regularly appearing in business contracts, RFR also has implications for any situation where long-term investment emerges naturally. An example is investment in personal education. Low-income families in developing countries may only be able to support formal education for one sibling (Song, Appleton and Knight, 2006). Applied to this situation, RFR suggests that the child who first begins education has the right to persist in his/her schooling. Other siblings would then expect to receive the return on the education by connecting with their educated sibling, i.e., the family forms a star network. Coordinating on educational outcomes in this way is efficient, and similar advantages may be at play when deciding which person or group is to receive advantaged access to information and knowledge, e.g., the choice of which employees will receive special training or which scholars will receive research grants.

Our experiment design allows us to investigate the effect of RFR on improving stability and coordination in networks in a controlled environment. Note that in sequential play environments, RFR cannot be separated from investment limits. An advantage of simultaneous play environments is that the impact of RFR can be distinguished from that of investment limits.

\section{IV.3 Equilibria and Hypotheses}

\section{IV .3.1. Equilibria prediction ${ }^{27}$}

\footnotetext{
${ }^{26}$ The conditions we impose reduce the number of players' possible actions from 16 to 5 , which then subsequently reduce the number of possible network outcomes from 65536 to 512 .

${ }^{27}$ Our experiment includes repeated games with a random stopping rule, but we focus only on the analysis of the stage game equilibria as it is easy to show that a sequence of stage-game Nash equilibrium strategies is also a
} 
For all three simultaneous treatments (Sim_B, Sim_L and Sim_L_NoRFR), the stage-game equilibrium is identical to the one described in Section III and in Galeotti and Goyal (2010). It is easy to see that adding investment limits to this environment does not change the equilibrium predictions, because these limits only rule out certain non-equilibrium actions. Similarly, the existence of the right of first refusal does not affect the stage game equilibrium predictions since it only makes it (weakly) more likely for people to hold beliefs consistent with equilibrium outcomes.

For two sequential treatments (Seq_B and Seq_L), it is necessary to modify the stage game into its extensive form. It is easy to show that, under the parameter values as specified above, the unique subgame perfect Nash equilibrium for the extensive form game occurs when the first mover invests, and each subsequent player links to that investor. Further, because investment limits only rule out certain non-equilibrium play, it is straightforward to verify that this remains the unique SPNE in this case as well. Similarly, RFR would not alter the equilibrium prediction.

All in all, all five treatments in our study share a common equilibrium: the star networks.

\section{IV.3.2 Hypothesis}

Our above discussion suggests, in general, that network environments that include sequential decisions, investment limits, and the "right of first refusal," are expected to facilitate star network formation. The effects can be demonstrated in multiple ways. We discuss three possible measures that capture the effects of these institutional characteristics: equilibrium frequency, network stability, and individual rationality.

\section{- Frequency of Equilibrium}

We count a network graph as a star if and only if there is one member who chooses to invest in information and the other three agents send exactly one link to the sole investor. For each stage of the game, equilibrium frequency is found by dividing the total number of star networks by the total number of rounds in that stage game. Then, the mean frequency of star networks is found by averaging over the frequencies in the 24 stage games of each treatment.

subgame-perfect equilibrium in the repeated game. NE strategies other than found in the stage game might exist in these repeated game environments (as demonstrated by Folk Theorems). It is beyond the scope of this paper to provide a characterization of these additional equilibria. 
Hypothesis 1. Star networks emerge more frequently in environments characterized by sequential decisions, investment limits, and the RFR. In light of the above discussion, we expect the frequency of realized star networks to follow the order below (where $\mathrm{A}>\mathrm{B}$ denotes that the star networks are expected to occur more frequently in A than B):

1) Effect of sequential decisions:

Seq_B $>$ Sim_B; Seq_L $>$ Sim_L

2) Combined effect of investment limits and the RFR:

Sim_L $>$ Sim_B; Seq_L $>$ Seq_B

3) Effect of RFR alone (only in simultaneous environments):

Sim_L $>$ Sim_L_NoRFR

4) Effect of the investment limits alone (only in simultaneous environments):

Sim_L_NoRFR $>$ Sim_B

\section{- Network Stability}

Network configuration may change over time. The stability of a network is key to many real world applications, e.g., R\&D in business firms (Dodd et al, 2003). We use two measures to investigate the stability of networks among treatments: duration of equilibrium and duration of disequilibrium. For each stage, the duration of (dis-)equilibrium is calculated as the average number of consecutive (non-)star outcomes divided by the number of rounds in the stage. We then average this measure over all 24 stage games for each treatment.

Hypothesis 2. This hypothesis again follows from our argument that star networks are promoted by sequential decisions, investment limits, and the RFR. This implies that environments with these features should exhibit a longer mean duration of continuous star networks and, after falling out of equilibrium, a shorter mean duration of disequilibrium.

Specifically, we hypothesize the following regarding the mean duration of continuous star networks:

1) Effect of sequential decisions:

Seq_B $>$ Sim_B; Seq_L $>$ Sim_L

2) Combined effect of investment limits and the RFR:

Sim_L $>$ Sim_B; Seq_L $>$ Seq_B 
3) Effect of the RFR alone (only in simultaneous environments): Sim_L $>$ Sim_L_NoRFR

4) Effect of the investment limits alone (only in simultaneous environments):

Sim_L_NoRFR $>$ Sim_B

Similarly, we form hypotheses regarding the mean duration of disequilibrium after falling out of equilibrium. Note the direction of the effect is reversed from the first set of hypotheses, since the less time it takes to restore a star network, the better an institution is at promoting stability.

5) Effect of sequential decisions:

Seq_B $<$ Sim_B; Seq_L $<$ Sim_L

6) Combined effect of investment limits and the RFR:

Sim_L $<$ Sim_B; Seq_L $<$ Seq_B

7) Effect of the RFR alone (only in simultaneous environments):

Sim_L $<$ Sim_L_NoRFR

8) Effect of the investment limits alone (only in simultaneous environments):

Sim_L_NoRFR $<$ Sim_B

\section{- Individual Rationality}

Theory predict that for a rational player at any given time, if no player in the group invested in information, then the rational choice is to invest. While if at least one player in the group invested in information, then the rational choice is to send a link to the investor. Our individual rationality measure takes value 1 if a subject makes a choice consistent with rationality, and 0 otherwise.

It is possible, in principle, to have a high mean individual rationality, while also having a low frequency of equilibrium (e.g., if three group members make systematically "good" decisions, but one member makes systematically "bad" decisions"). In general, however, we would expect high individual rationality in network formation games to imply faster convergence to star networks, as well as more stable network outcomes. Just as above, we expect sequential decision-making, investment limits and the "right of first refusal" to each promote individual rationality. 
Hypothesis 3. Individual rationality is greater in environments characterized by sequential decisions, investment limits and the RFR.

1) Effect of sequential decisions:

Seq_B $>$ Sim_B; Seq_L $>$ Sim_L

2) Combined effect of investment limits and the RFR:

Sim_L $>$ Sim_B; Seq_L $>$ Seq_B

3) Effect of the RFR alone (only in simultaneous environments):

Sim_L $>$ Sim_L_NoRFR

4) Effect of the investment limits alone (only in simultaneous environments):

Sim_L_NoRFR $>$ Sim_B

\section{IV.4. Experimental Procedure}

The experiment sessions were conducted between December 2010 and March 2011 in the ICES laboratory at George Mason University. Subjects were recruited via email from registered students at George Mason University. Each subject participated in only one session and none had previously participated in a similar experiment.

In total, 160 subjects participated in the computerized experiment programmed with zTree (Fischbacher 2007). Each experimental session lasted between 120 and 150 minutes. Subjects' total earnings were determined by the Experimental Dollars (E\$) earned at the end of the experiment, which were then converted at a rate of $\mathrm{E} \$ 3$ per US dollar. The average earnings were $\$ 25.28$, ranging from a maximum of $\$ 53$ to a minimum of $\$ 8$ across all sessions.

In all treatments, before a session started, subjects were seated in separate cubicles to ensure anonymity. They were informed of the rules of conduct and provided with detailed instructions (see appendix B for the instruction of Sim_B as an example). The instructions were read aloud. In order to guard against confusion, after subjects finished reading the instructions, they were asked to complete a quiz. An experimenter checked their answers. Then the experiment worked through the quiz questions on a white board in front of the laboratory. The experiment began after all subjects confirmed they had no further questions.

We ran 2 sessions for each treatment condition. Thus, in the end, we obtained 672 network graphs for each treatment (excluding the practice stage). Most of our analysis assumes 
24 observations (eight groups each of which plays three stage-games with perfect strangers) for each treatment.

\section{Results}

We present results in the order of hypotheses listed in Section III.3. First, we discuss results concerning the frequency of star networks with an extended analysis on network centrality. Then we investigate two network stability measures: the duration of equilibrium and disequilibrium. Third, we look at the stability on decision making at individual level. Finally, we discuss the measure of individually rational and how it varies across treatments and over time.

\section{V.1.1 Frequency of Star Networks}

The mean frequency of star networks in each of our treatments is shown in Figure 1. It is clear from this figure that star networks emerge at different rates, with baseline treatments displaying the lowest frequency of star networks. More formally, our findings are as follows:

\section{Figure 1. Mean frequency of star networks (in \%) by treatment}

*Note: standard error shown in marks

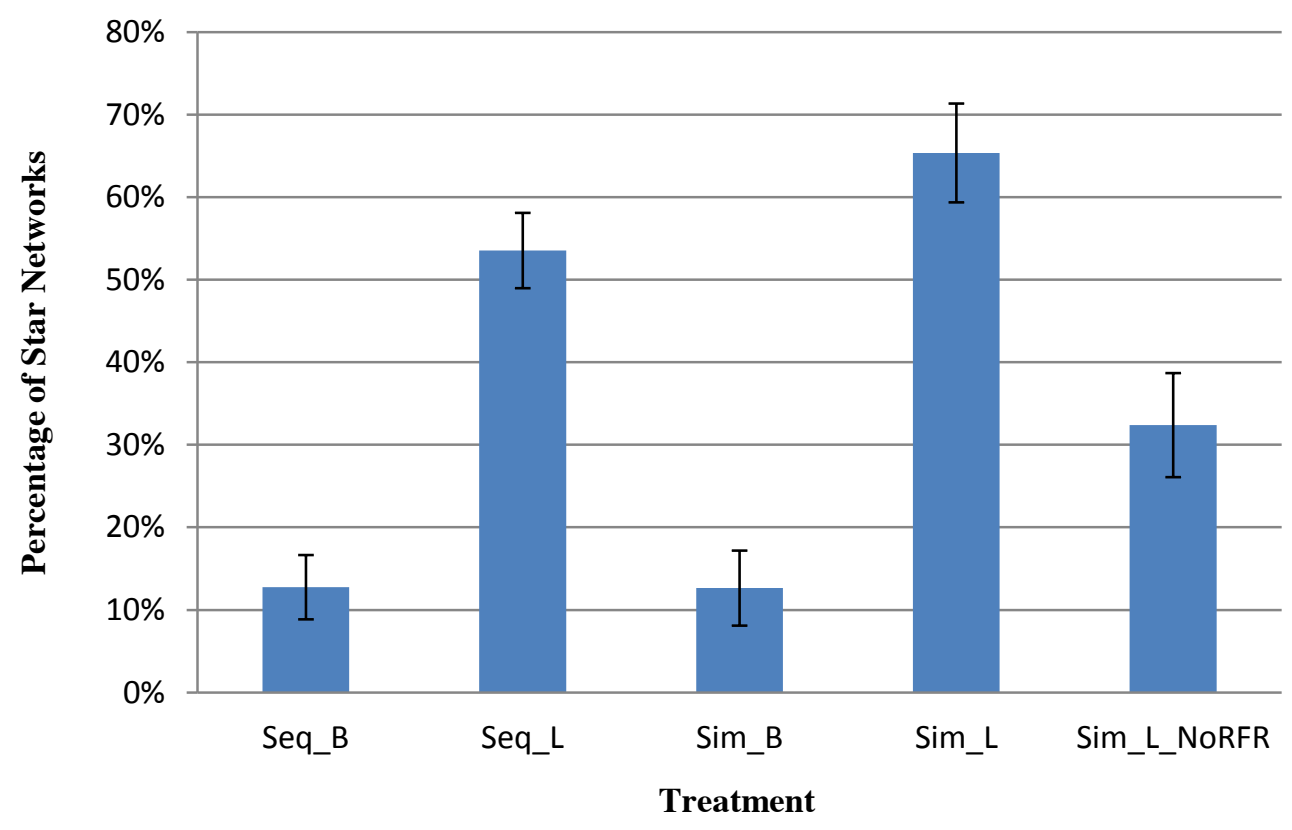




\section{Result 1. (Test of hypothesis 1.1) Sequential decisions do not increase the frequency of star} networks.

We found star networks to emerge with frequency $12.6 \%$ and $12.7 \%$ in Sim_B and Seq_B, respectively $\left(\mathrm{p}=0.667^{29}\right)$. On the other hand, when investment limits and the RFR are both present, $53.5 \%$ of networks formed in Seq_L are star shaped in comparison to $65.3 \%$ in Sim_L; this is also insignificant at standard levels $(\mathrm{p}=0.054)$.

\section{Result 2. (Test of hypothesis 1.2) More star networks emerge when investment limits combined with the RFR are present.}

Sim_L generated $65.3 \%$ of star networks, while only $12.6 \%$ of networks in Sim_B are star shaped. This difference is significant ( $\mathrm{p}<0.001)$. Agents in Seq L form star networks 53.5\% of time. When compared with the $12.6 \%$ in Seq $B$, the difference is again significant $(\mathrm{p}<0.001)$. Thus, our data provide clear evidence supporting the positive impact of investment limits and the RFR on star network formation.

\section{Result 3. (Test of hypothesis 1.3) The RFR promotes star network formation in simultaneous decision environments.}

The right most two bars in Figure 1 correspond to Sim_L and Sim_L_NoRFR. The only difference between these two treatments is that the RFR is present in the former but absent in the latter. In Sim_L star networks emerge at a rate of $65.3 \%{ }^{30}$. The frequency in Sim_L_NoRFR treatment $(32.4 \%)$ is significantly lower than this $(\mathrm{p}=0.0016)$. This is evidence that the RFR promotes star networks in simultaneous environment.

\section{Result 4. (Test of hypothesis 1.4) In simultaneous environments star networks emerge more frequently with than without investment limits.}

Sim_L_NoRFR generates star networks at a rate of $32.4 \%$, while the frequency in Sim_B is $12.6 \%(\mathrm{p}=0.0034)$. Thus, investment limits promote star networks under simultaneous decision-making.

\footnotetext{
${ }^{29}$ Unless otherwise indicated, all p-value refers to two-tailed Mann-Whitney test.

${ }^{30}$ The frequency of star network we found here, $65.3 \%$, is much higher than the best case in Goeree et al (2009) with agent heterogeneity condition.
} 
Figure 2. Mean frequency of star network $(\%)$ over time

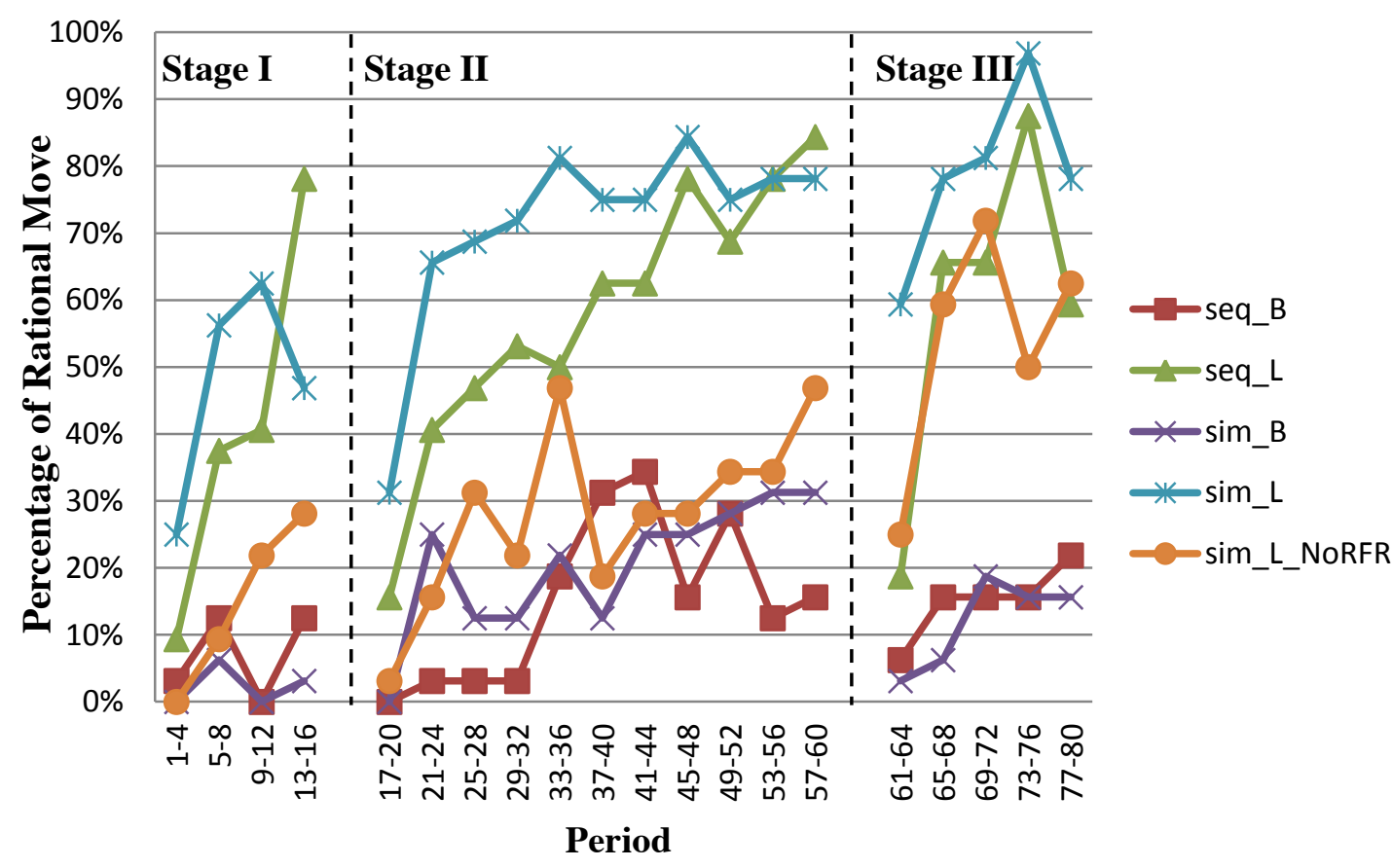

\section{Result 5. (Time Trend) More star networks are formed in later rounds of the experiment in Sim_L,Seq_L and Sim_L_NoRFR.}

Figure 2 depicts the mean frequency of star networks over time. In all treatments the frequency of equilibrium is low in early rounds and then increases. Despite this common increase, when considering only the final five rounds, we can reject the hypothesis that mean frequencies of star networks are the same in all treatments (Kruskal-Wallis test, $p=0.0006$ ).

To analyze differences in the rate at which equilibrium changes over time and between treatments, we use an OLS regression with fixed effects at the group level. The results are described in Table 3. The key finding is that Seq_L displays a statistically significantly higher rate of increase in star networks over time than any other treatment (see Table 4). In contrast, Sim_B and Seq_B have the lowest rates among all treatments (Chow test, maximum p-value less than 0.0028 , See table 4 ). 
Table 3. Linear Regression on the evolution of star network frequency

\begin{tabular}{|c|c|c|c|c|c|c|c|c|c|c|}
\hline & \multicolumn{2}{|c|}{ Seq_B } & \multicolumn{2}{c|}{ Seq_L } & \multicolumn{2}{c|}{ Sim_B } & \multicolumn{2}{c|}{ Sim_L } & \multicolumn{2}{c|}{ Sim_L_NoRFR } \\
\hline \multirow{2}{*}{ round } & 0.0053 & 0.0053 & 0.0158 & 0.0158 & 0.0057 & 0.0057 & 0.0072 & 0.0072 & 0.0083 & 0.0083 \\
& $(0.000)$ & $(0.000)$ & $(0.000)$ & $(0.000)$ & $(0.000)$ & $(0.000)$ & $(0.000)$ & $(0.000)$ & $(0.000)$ & $(0.000)$ \\
\hline \multirow{2}{*}{ stage } & -0.128 & -0.128 & -0.419 & -0.419 & -0.133 & -0.133 & -0.096 & -0.096 & -0.0641 & -0.0641 \\
& $(0.005)$ & $(0.004)$ & $(0.000)$ & $(0.000)$ & $(0.006)$ & $(0.001)$ & $(0.114)$ & $(0.094)$ & $(0.282)$ & $(0.247)$ \\
\hline \multirow{2}{*}{ constant } & 0.1827 & 0.1826 & 0.7644 & 0.7644 & 0.1906 & 0.1906 & 0.5775 & 0.5775 & 0.1117 & 0.1117 \\
& $(0.001)$ & $(0.000)$ & $(0.000)$ & $(0.000)$ & $(0.001)$ & $(0.000)$ & $(0.000)$ & $(0.000)$ & $(0.107)$ & $(0.083)$ \\
\hline fe(group) & $\mathrm{N}$ & $\mathrm{Y}$ & $\mathrm{N}$ & $\mathrm{Y}$ & $\mathrm{N}$ & $\mathrm{Y}$ & $\mathrm{N}$ & $\mathrm{Y}$ & $\mathrm{N}$ & $\mathrm{Y}$ \\
\hline $\mathbf{R}^{2}$ & 0.0310 & 0.0981 & 0.1200 & 0.1528 & 0.0353 & 0.3262 & 0.0661 & 0.1771 & 0.1196 & 0.2478 \\
\hline
\end{tabular}

Table 4. Chow test for the same slope of regression (p-value)

\begin{tabular}{|l|l|l|l|l|}
\hline & Seq_B & Seq_L & Sim_B & Sim_L \\
\hline Seq_L & 0.0007 & - & - & - \\
\hline Sim_B & 0.6515 & 0.0017 & - & - \\
\hline Sim_L & 0.0011 & 0.7743 & 0.0028 & - \\
\hline Sim_L_NoRFR & 0.0000 & 0.0000 & 0.0000 & 0.0468 \\
\hline
\end{tabular}

\section{V.1.2 Network Centrality}

Networks are said to have high centrality when a small number of people have a large number of connections. So, for example, network centrality is highest in our environment when one person receives three links, and no others receive any links, as occurs in a star network. It is lowest, on the other hand, when everyone sends links to each other person. Here we take a similar approach to Georee et al (2008) and report the "degree centrality" per group. The following equation gives the formal definition of this measure:

$$
\text { degree-centrality }=\frac{1}{(n-1)(n-2)} \sum_{i \in N}\left[\max _{j \in N} \text { degree }_{j}-\text { degree }_{i}\right]
$$

where $N=\{1,2, \ldots n\}$ is the set of agents in the network, while $i$ and $j$ are two typical members of the set.

The above equation normalizes the centrality measure of a star network to be one. Intuitively, centrality measures closer to one suggest the network is more similar to a star. Our goal is to determine whether agents form networks that are more star-like over time and whether this tendency differs between treatments. 


\section{Result 6. Centrality is higher in treatments with investment limits and the RFR.}

Figure 3 shows the mean degree centrality under each treatment condition. After Bonferroni correction for multiple comparisons, the difference between Sim_B and Sim_L, Seq_B and Seq_L remains statistically significant ( $p=0.000$ and 0.078 respectively). Thus, under investment limits and the RFR, more star-like networks form in both sequential and simultaneous environments.

\section{Figure 3. Mean degree centrality measure by treatment}

*Note: standard error shown in marks

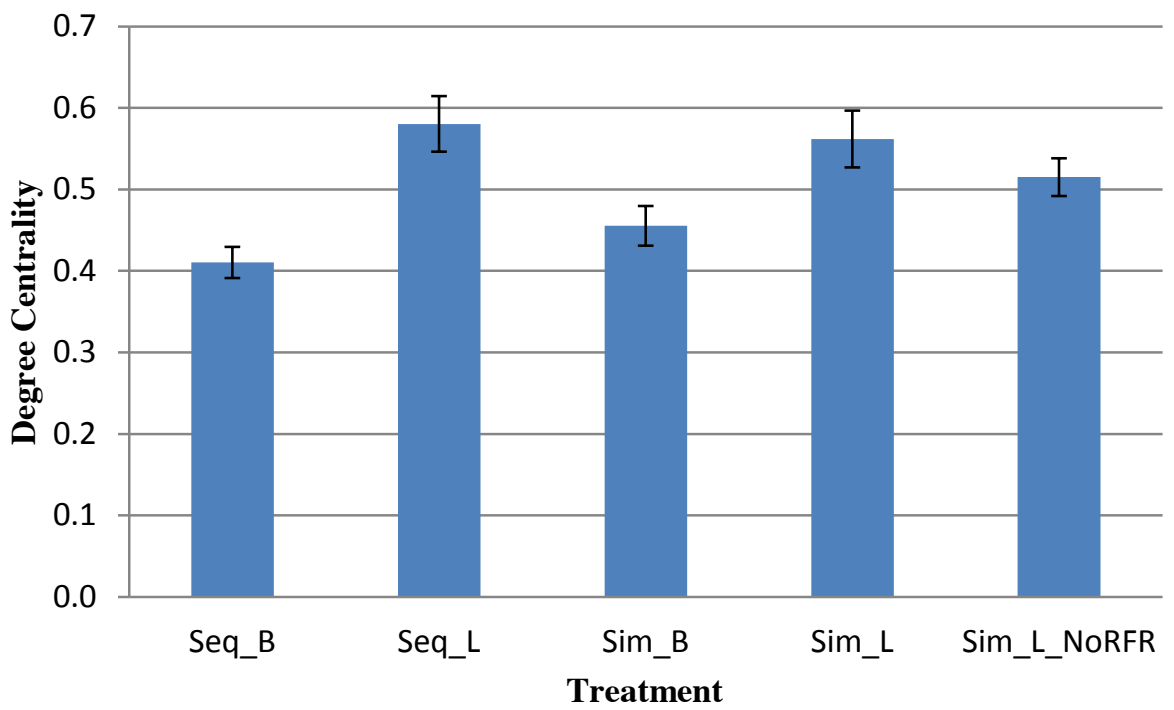

\section{IV.2 Stability of Star Networks}

We consider two measures of stability: (1) once a star network formed, how many rounds does it last? (2) after falling out of equilibrium, how many rounds does it take to restore a star network? Figure 4 demonstrates the average length of continuous star networks (in percentage term) across treatments.

\section{Result 7. (Test of hypothesis 2.1) Sequential decisions do not reduce the duration of star networks.}

In Sim_B, once a star network forms, it will last on average for only 2.1 rounds $(7.5 \%$ of the total number of rounds in a stage game). In Seq_B, however, star networks sustain 
themselves for an average of 2.24 rounds. The difference is not statistically significant (Mann_Whitney two tailed, p=0.6201). Similarly, when comparing results in Sim_L (29.8\%) and Seq_L (44.5\%), we cannot reject the null hypothesis that their equilibrium duration is identical $(\mathrm{p}=0.2742)$.

Figure 4 The length of continuous equilibrium networks (\%) by treatment

*Note: standard error shown in marks

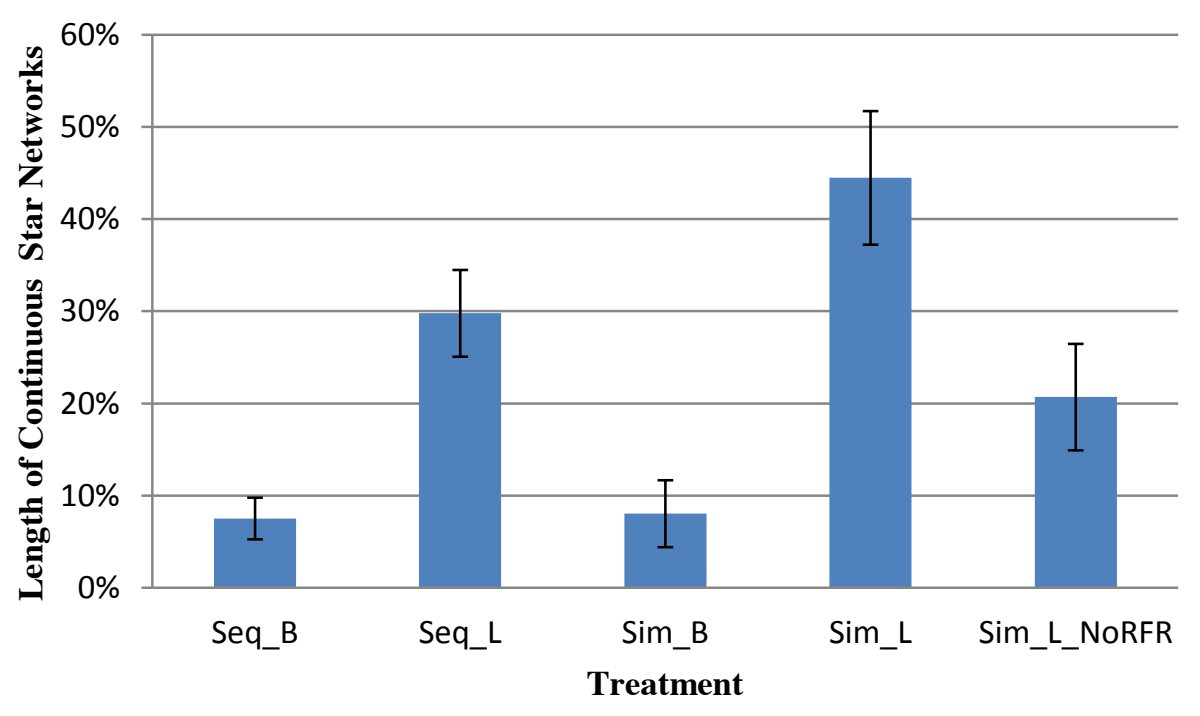

\section{Result 8. (Tests of hypotheses 2.2, 2.3 and 2.4) Star network duration is longer in treatments with investment limits or RFR.}

Observed duration for continuous star networks parallels the results found regarding the frequency of equilibrium.

In simultaneous environments, when investment limits are introduced (Sim_L_NoRFR), the average length of continuous star network increases to 5.8 rounds, a significant increase from the result of 2.1 rounds in Sim_B ( equilibrium network increases to 12.46 rounds $^{31}$, a significant difference compared both to Sim_L_NoRFR and Sim_B $(\mathrm{p}=0.0032$ and $\mathrm{p}<0.001$ respectively $)$.

\footnotetext{
${ }^{31}$ The longest-lasting star network occurs in Sim_L treatment, wherein a group of subjects kept playing a single star network for 43 rounds in their 44-round stage game without disruption.
} 
In the sequential environment, the same institutions of investment limits and the RFR are introduced. In Seq_L, star networks last for about 8.34 rounds in a 28-round stage game ${ }^{32}$. Agents in Seq_L do not sustain the same star as long as they did in Sim_L $(p<0.001)$.

Result 9. (Test of hypothesis 2.5) Sequential decisions do not shorten the duration of disequilibrium in the Baseline condition, but do under investment limits.

Figure 5 shows that the duration of disequilibrium before reestablishing a star network does not differ between Sim_B and Seq_B $(p=0.7142)$, while it does between Sim_L and Seq_L $(p=0.0371)$.

Figure 5. The length of continuous disequilibrium networks by treatment

*Note: standard error shown in marks

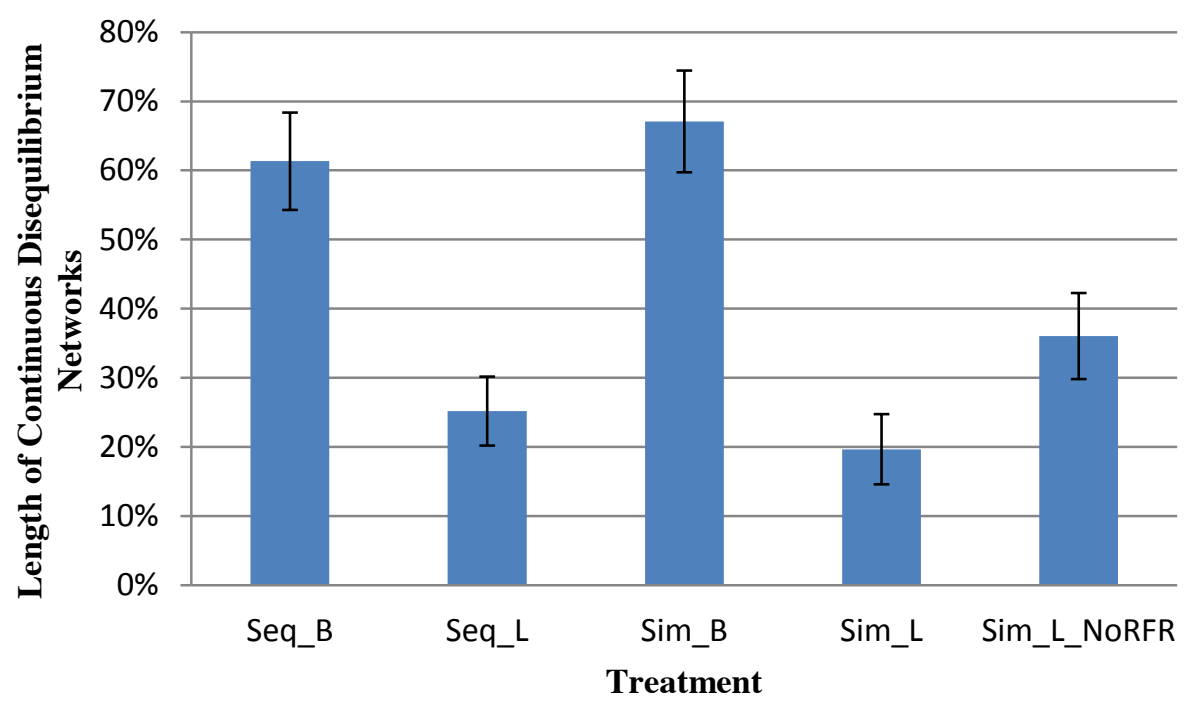

\section{Result 10. (Test of hypothesis 2.6, 2.7, 2.8) Disequilibrium durations are shorter under investment limits or the RFR.}

Our data support hypotheses 2.6 and 2.7. Comparing Sim_L_NoRFR to Sim_L, the disequilibrium length falls from 10.1 rounds to 5.5 rounds, a significant decrease $(p=0.014)$. In Sim_B and Sim_L it takes on average 17.2 and 5.5 rounds to return to equilibrium after a

\footnotetext{
${ }^{32}$ The length of the stage games varies among stages, with an average of 28 rounds. The average length of continuous equilibrium is calculated as $\frac{n_{1} / 16+n_{2} / 44+n_{3} / 24}{3} \times 28$ where $n_{i}$ is the average number of rounds in continuous equilibrium in stage $i$.
} 
disruption. In Seq_B and Seq_L it takes 18.8 and 7 rounds on average to return to equilibrium play. Both comparisons are statistically significant $(\mathrm{p}<0.001)$.

\section{V.3 Stability of Individual Choices}

This section investigates the stability of individual decisions. A player makes four decisions per period (one purchasing and three linking decisions), and our strategy is to determine the mean percentage of changed decisions between period $t-1$ and $t$. The result is plotted in Figure 6 by treatment condition. We analyze data from the sequential and simultaneous treatments separately, because our sequential environment allows fewer changes in choice, and consequently our stability measure is not directly comparable between these two environments ${ }^{33}$.

\section{Figure 6. Mean percentage of choice change by treatment}

*Note: standard error shown in marks

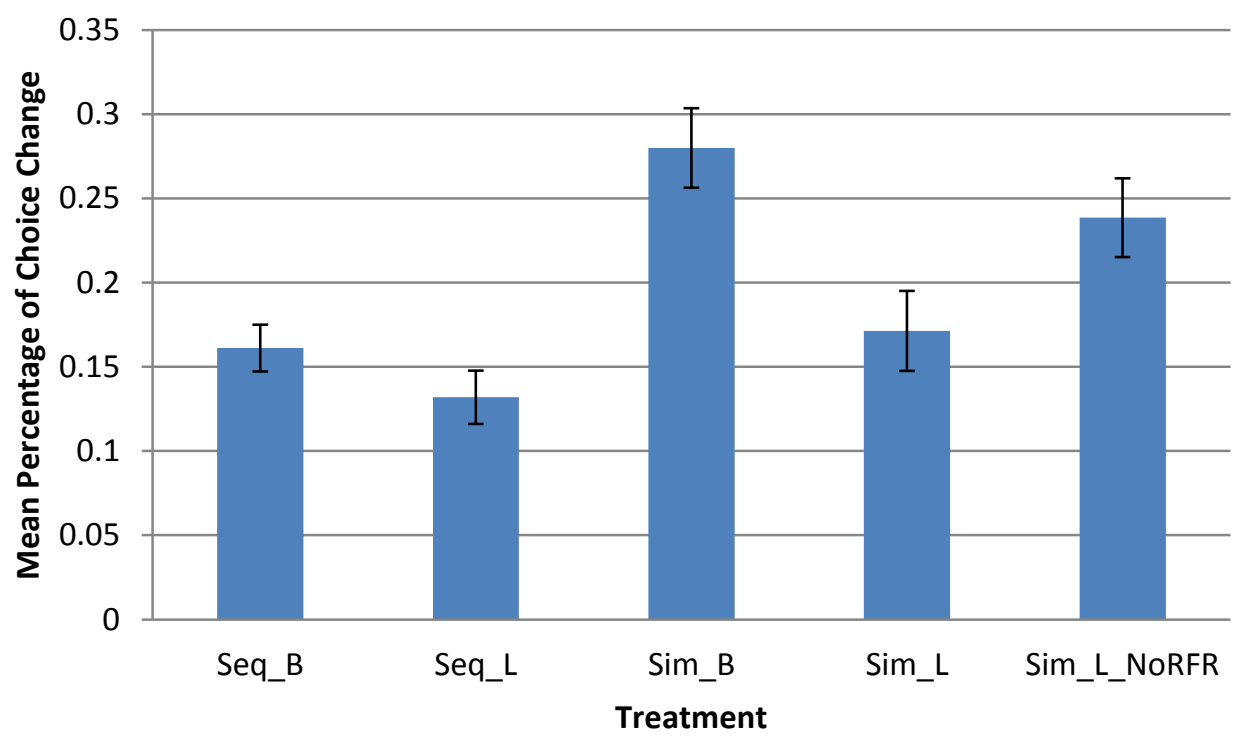

\section{Result 11. Among the three simultaneous treatments, institutions that generate more equilibrium networks also have exhibit greater choice stability.}

\footnotetext{
${ }^{33}$ Unlike the simultaneous treatments that allow decision changes each period, players in sequential environments are able to change their choices only once every four periods. An alternative stability calculation for the sequential environments includes only periods at which a player can change their decision. With this measure (which remains incomparable to the simultaneous treatments), the Seq_B players change about $52.58 \%$ of their choices each period and Seq_L players change about $40.36 \%$ of their choices per period.
} 
Players in Sim_B change on average $27.99 \%$ of their choices each period, significantly higher than the frequency of change, $17.13 \%$, in Sim_L ( $p=0.0035)$. Players in Sim_L_NoRFR make $23.85 \%$ of their choices per period. This is higher than Sim_L ( $p=0.0254)$ and lower, although not statistically significantly, than Sim_B $(\mathrm{p}=0.1546)$.

\section{Result 12. Among the two sequential treatments, institutions that generate more equilibrium networks also exhibit greater choice stability.}

The average percentage of choice change in Seq_B and Seq_L is 16.11 and 13.19 respectively. The difference between them are statistically significant $(\mathrm{p}=0.001)$

\section{V.4 Individual Rationality}

We define a decision to be rational if it satisfies both of the following conditions: (1) if any other agent has invested in information, one should link to her; (2) if no other agent has invested in information, one should invest. The percentages of decisions that satisfy these conditions are plotted in Figure 7 for each treatment condition.

Figure 7. Mean percentage of rational choices made by treatment

*Note: standard error shown in marks

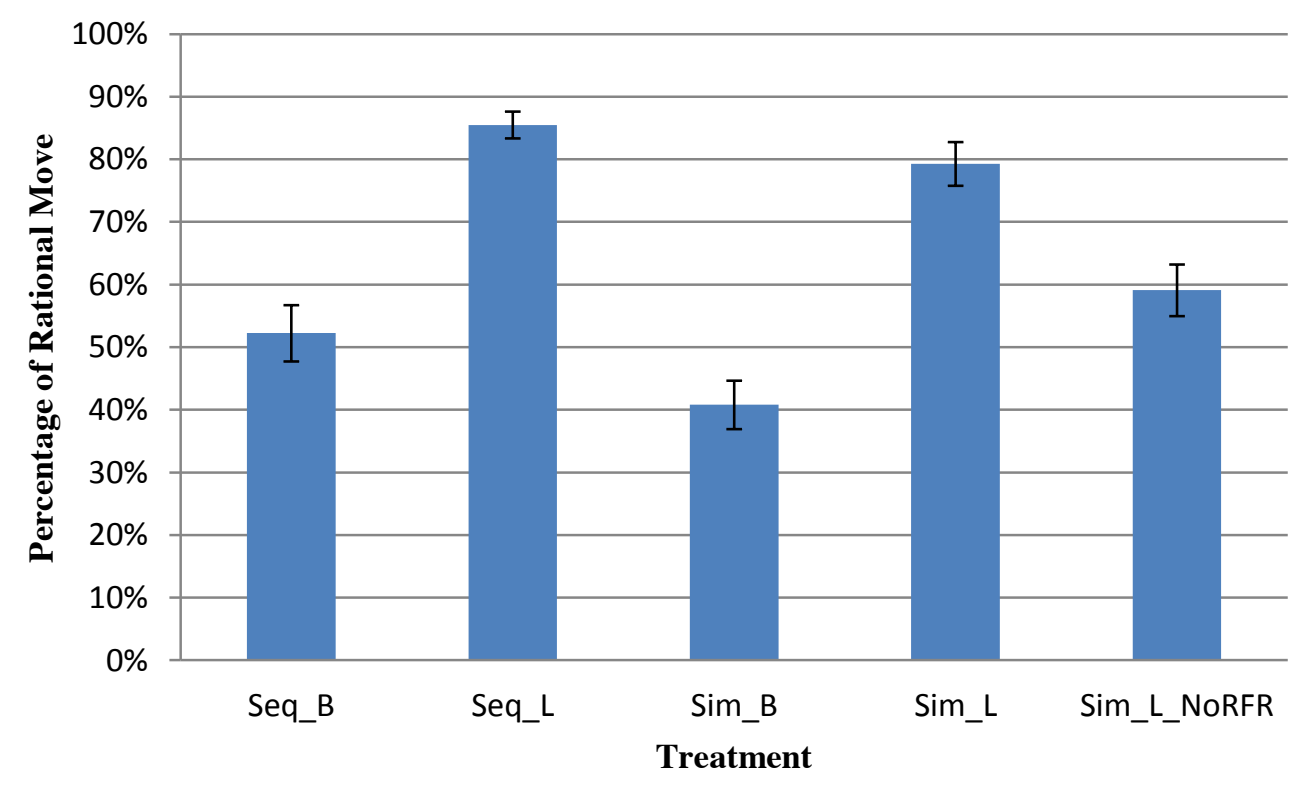




\section{Result 13. (Test of hypothesis 3.1) Sequential decisions do not improve individual rationality.}

We find no statistically significant differences in individual rationality between Sim_B and Seq $\_$B $(p=0.0512)$ or between Sim_L and Seq_L $(p=0.2879)$.

\section{Result 14. (Test of hypothesis 3.2)The combination of investment limits and the RFR promotes rational choice at individual level.}

In simultaneous environments, about $40.8 \%$ of choices made are rational in the baseline condition, while in Sim_L, the number increases significantly to $79.3 \%(p<0.001)$. In sequential environments, the effect is smaller (an increase from $52.2 \%$ to $85.5 \%$ ) but remains highly significant $(\mathrm{p}<0.001)$.

\section{Result 15. (Test of hypothesis 3.3)The RFR alone increases individual rationality in the simultaneous environment.}

The last two bars in Figure 7 show that the existence of the RFR improves individual rationality. About 51.9\% of choices made in Sim_L_NoRFR are individually rational, a significant decrease in comparison to Sim_L $(p=0.0023)$.

\section{Result 16. (Test of hypothesis 3.4) Investment limits promote rational choice at the individual level in simultaneous environments.}

The percentages of individual rational moves for Sim_L_NoRFR and Sim_B were 59.1\% and $40.8 \%$ respectively $(\mathrm{p}=0.0010)$.

\section{Behavioral Rules}

The purpose of this section is to draw inferences about the behavioral rules of individuals in our various treatments. Our maintained assumption is that behavioral rules in all treatments are formed using elements from a menu of information that are finite and identical, but that different treatments lead to rules that differ at the level of usage on the information. Without ex ante knowledge of what kind of rules may exist, we use cluster analysis to detect them ${ }^{34}$.

\footnotetext{
${ }^{34}$ Cluster analysis, as a numerical method for classification, serves the function of organizing a large and complicated data set into a small number of groups of objects so that the original data set could be easily understood
} 
Compared to regressions, cluster analysis can better explore patterns within a complex environment where the classification structure may not be well defined. It allows us to explore behaviors among individuals without the need to pre-define the nature or number of possible rules (see also Houser et al, 2004).

In this section, we first discuss our method for cluster analysis (the k-means algorithm) and then describe how we implemented cluster analysis with our data.

\section{VI.1. The k-means clustering algorithm}

With cluster analysis, one develops indices and criteria to know in a mathematically precise way how "close" or "far apart" objects are to each other. A variety of distance measures have been proposed. The one we use here is Euclidean distance:

$$
d_{i j}=\left[\sum_{k=1}^{p}\left(x_{i k}-x_{j k}\right)^{2}\right]^{1 / 2}
$$

where $x_{i k}$ and $x_{j k}$ are, respectively, the $k^{\text {th }}$ variable value of a $p$-dimensional observations for individual $i$ and $j$.

An informative clustering includes groups such that the distance between objects in the same group is small, while the distance between groups is large. Based on this simple intuition, a variety of so-called "dissimilarity indices" (formed by combining distance measures across agents) have been suggested.

The particular index described below comprises the foundation for the k-means clustering algorithm, which we use to perform our analysis. Let $d_{q l, k v}$ be the Euclidean distance between the $l^{\text {th }}$ object in the $q^{\text {th }}$ group and the $v^{\text {th }}$ object in the $k^{\text {th }}$ group. Then the k-means dissimilarity index takes the following form:

$$
h_{1}(m)=\sum_{m=1}^{g} \frac{1}{2 n_{m}} \sum_{l=1}^{n_{m}} \sum_{v=1}^{n_{m}} d_{m l, m v}^{2}
$$


This index measures the within sum of square, i.e., the sum of squared distances between an object in cluster group $m$ and the mean of all objects that belong to group $m^{35}$.

Ideally, one would be able to go through all combinations of objects to determine the one that yields the lowest dissimilarity index within each group. However, when the number of objects is not small, it becomes extremely computationally burdensome to do $\mathrm{so}^{36}$. This has led scholars to develop numerical algorithms to approximate clustering solutions; among these, kmeans is used most widely (Steinley, 2006).

Our analysis is based on a canonical k-means algorithm (Hartigan and Wong, 1979). It involves iteratively updating partitions by relocating objects into the group whose mean is closest and then recalculating group means.

\section{- Determining the number of clusters}

A cluster analysis requires one to determine the number of clusters a dataset contains. A large variety of methods have been proposed for this purpose. In a Monte Carlo analysis, Milligan and Cooper (1985) report that among 30 methods they compared, the top performer was Calinski and Harabasz (1974) (which we denote by C-H $)^{37}$. We use C-H to determine the number of clusters in our data.

$\mathrm{C}-\mathrm{H}$ suggested that the number of clusters, $\mathrm{g}^{*}$, should be chosen to maximize $\mathrm{C}(\mathrm{g})$, where $\mathrm{C}(\mathrm{g})$ is given by:

$$
C(g)=\frac{\operatorname{trace}(B)}{g-1} / \frac{\operatorname{trace}(W)}{n-g}
$$

where B is the usual between (clusters) sum of squared deviations from (overall) mean, and W the within (clusters) sum of squared deviations from (cluster) mean.

\section{VI.2. Results from k-means analysis}

Our analysis proceeds in two steps. First, we estimate for each individual the parameters that characterize the way they make decisions given information. Then, we use cluster analysis to

\footnotetext{
${ }^{35}$ Indices that measure the separation between groups are also used in many other methods. We refer interested readers to Everrit et al (2011).

${ }^{36}$ According to Liu (1968), the number of possible partitions one must consider in order to partition 100 network agents into five groups is $6.6^{*}\left(10^{\wedge} 67\right)$.

${ }^{37}$ Another successful technique developed by Duda and Hart (1973) works with hierarchical cluster methods. The network data do not fit these types of cluster analysis.
} 
group similar individuals into behavioral rules. In particular, we run a linear regression for each individual with the decision to invest (or not) as a binary dependent variable, on a constant, a dummy for whether investing is rational and an index characterizing the subjects investing behavior in the previous two rounds ${ }^{38}$ (see also Kurzban and Houser, 2005). Then, we use the kmeans algorithm to cluster these estimates into groups of behavioral rules. We repeat the above analysis for the linking decision.

\section{VI.2.1 Behavioral rule parameters}

The independent variables we include in our regressions are meant to capture a person's: (i) base rate willingness to invest or link to others (captured by the regression's constant); (ii) consistency with individual rationality (captured by the a dummy variable that takes value one if it is optimal to invest (or link)); and (iii) propensity to form a "habit" of choice in the sense that they do what they did before (captured by the variable indicating the lagged decisions for the past 2 rounds). Equations 7 and 8 specify our regression equations for investing and linking respectively:

$$
\begin{aligned}
& \text { invest }_{i, t}=\beta_{1} * \text { rational }_{i, t}^{p}+\beta_{2} * \sum_{s=1}^{2} \text { invest }_{i, t-s}+\beta_{3}+\varepsilon_{i, t} \\
& \text { linksending }_{i, t}=\gamma_{1} * \text { rational }_{i, t}^{l}+\gamma_{2} * \sum_{s=1}^{2} \text { linksending }_{i, t-s}+\gamma_{3}+\delta_{i, t}
\end{aligned}
$$

where

$$
\begin{aligned}
& \text { rational }_{i, t}^{p}=\left\{\begin{array}{l}
1, \text { if subject } \mathrm{i} \text { should have purchased information at round } \mathrm{t} \\
\text { according to individual rationality } \\
0, \text { otherwise }
\end{array}\right. \\
& \text { rational }_{i, t}^{l}=\left\{\begin{array}{l}
1, \text { if subject } \mathrm{i} \text { should have sent link at round } \mathrm{t} \\
\text { according to individual rationality } \\
0, \text { otherwise }
\end{array}\right. \\
& \text { invest }_{i, t-s}=\left\{\begin{array}{l}
1, \text { if subject } \mathrm{i} \text { invested in information in round } \mathrm{t}-\mathrm{s} \\
0, \text { otherwise }
\end{array}\right. \\
& \text { linksending }_{i, t-s}=\text { number of links subject i sent in round } \mathrm{t}-\mathrm{s}
\end{aligned}
$$

\footnotetext{
${ }^{38}$ We use the sum of past two choices as a proxy for past choice in this analysis since the immediate past choices are highly likely to be collinear with our dependent variables in all treatments with investment limits.
} 
The above regressions are repeated for each individual. We end up with 142 and 152 subjects in our sample for the investing and linking regressions, respectively ${ }^{39}$. Each individual's estimates can be represented by a point in 3-space (See Appendix C, panels a and b).

\section{I.2.2 K-means clustering}

We implement our k-means cluster analysis, as well as cluster number selection, using $\mathrm{R}^{40}$. Based on the $\mathrm{C}-\mathrm{H}$ index, we find three clusters in both investing and linking decisions ${ }^{41}$ (See Appendix C, panel a and b, for the 3-space plot).

\section{a) Investing decisions}

The three panels of Figure 8 are the three 2-space projections of the estimates $\left\{\beta_{1}, \beta_{2}, \beta_{3}\right\}$ from regression on investing decisions (Equation 7) into corresponding 2-space . Each point represents an individual's estimates from his/her investing decisions regression. Points with the same marker belong to the same cluster.

\section{Figure 8. Projections of Estimates from Investing Decision}

(a)

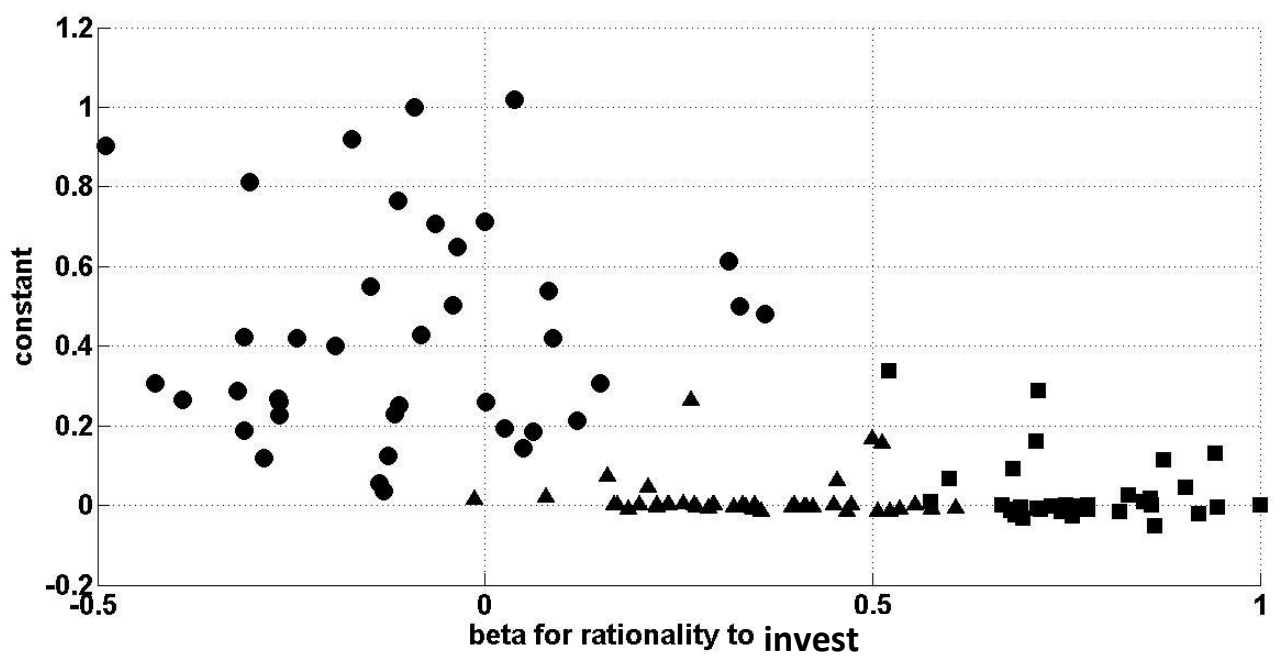

\footnotetext{
${ }^{39}$ We drop 18 subjects for regressions on investing decisions, as there is zero variation in dependent variables. For the same reason, we drop 8 subjects for regression on linking decisions.

${ }^{40}$ We have found substantial differences in K-means clustering results produced by the standard packages in Stata, $\mathrm{R}$ and Matlab. We traced it to differences in the specific numerical algorithms used by each package (Steinley, 2008) and decided to adopt clustering package from $\mathrm{R}$, as it is most robust to the choice of initial points. In particular, we use kmeansruns from package cluster and initialize the same clustering analysis with 1000 different starting points. ${ }^{41}$ Decision rules for investing and linking differs in terms of interpretation and the range of measurement. Hence, we discuss them separately.
} 
(b)

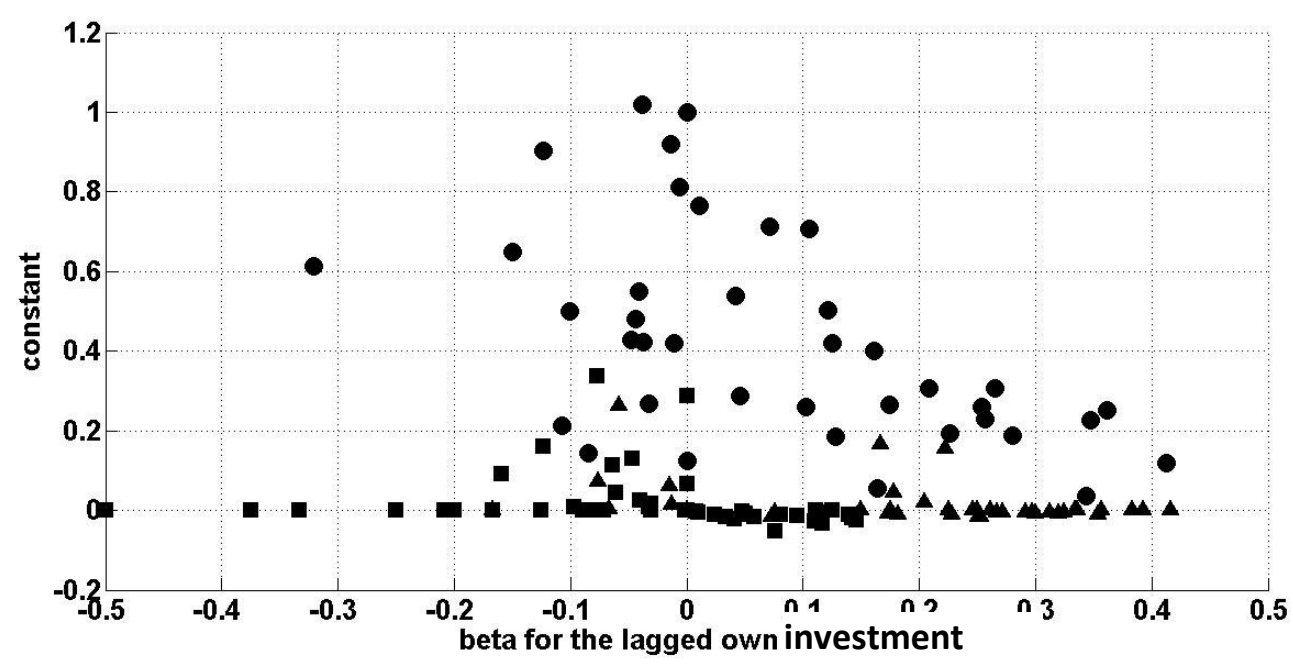

(c)

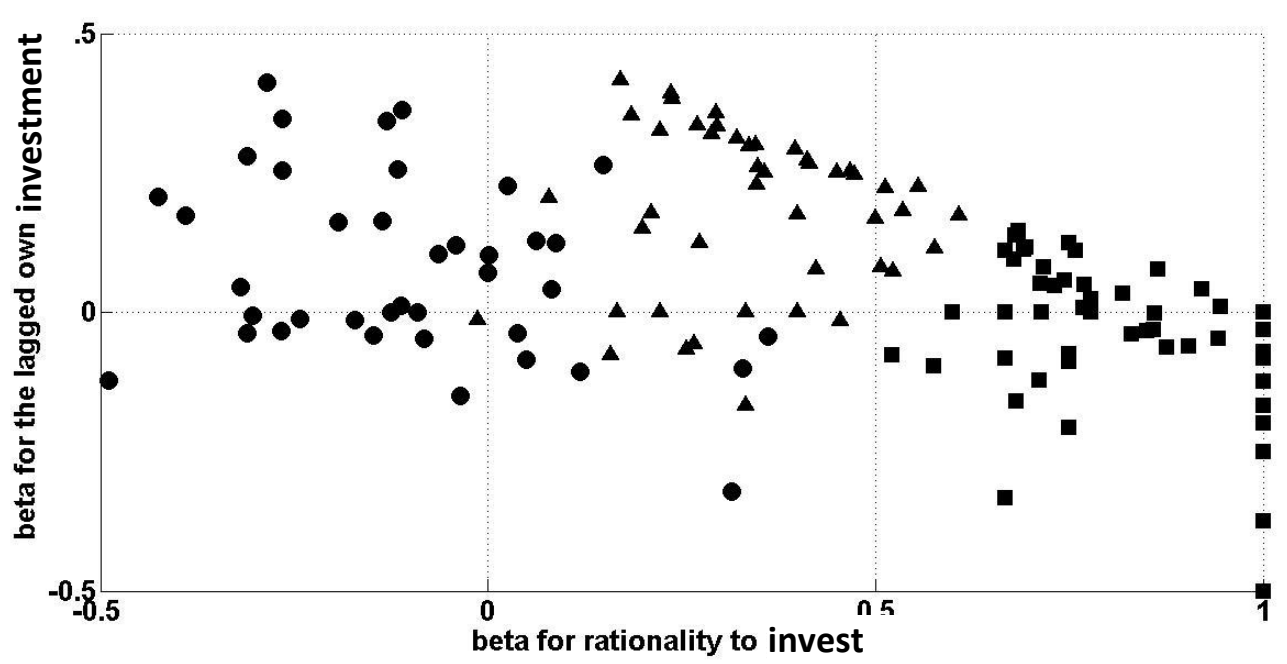

It is clear from visual inspection that our clusters are well-separated. To provide statistical evidence on the strength of this separation, we analyze the separation along each independent variable's axis. Mann-Whitney tests find significant differences between all pairs of clusters in each axis $(\mathrm{p}<0.001)$, with the exception of the constants in the triangle and round clusters (the lack of separation in this single case can be clearly seen from panels (a) or (b)).

Not only are the clusters clearly separated, the location of the clusters also carries meaningful interpretation in our sample. Table 5 provides the mean estimate for each 
independent variable and for each cluster, and also reports whether that mean is significantly different from zero.

Table 5. The Mean of Estimates from Regression on Investing Decision

\begin{tabular}{|l|l|l|l|}
\hline & Square cluster & Triangle cluster & Round cluster \\
\hline Rational to invest & 0.8190 & 0.3411 & -0.0978 \\
& $(0.0000)$ & $(0.0000)$ & $(0.0054)$ \\
\hline Lagged choice & -0.0408 & 0.1745 & 0.0782 \\
& $(0.1480)$ & $(0.0000)$ & $(0.0120)$ \\
\hline Base rate(constant) & 0.0175 & 0.0137 & 0.4279 \\
& $(0.2589)$ & $(0.7066)$ & $(0.0000)$ \\
\hline Number of subjects & 57 & 46 & 39 \\
\hline
\end{tabular}

Note: $p$-value from Wilcoxon signed-rank test in parentheses

Based on the results from Table 5, we summarize the characteristics of the three clusters that define the three behavioral rules used by our subjects.

(1) We define the cluster indicated with circular markers as the "Rational" type. People that belong to this cluster are guided by the rationality of the current opportunity to invest. They focus relatively less on their past choices, and their base rate of investing is near zero. Consequently, if it is neither rational to invest nor had they invested before, the subjects in this group would be relatively unlikely to invest.

(2)We define the cluster indicated by triangle markers as the "Habit" type. Subjects in this cluster are guided by rationality, but relatively less so than the Rational type. Instead, their current decisions follow closely their past decisions. As with the "Rational" type, the base rate of investing of the Habit type is near zero.

(3) We define the cluster indicated by square markers as the "Dogmatic" type. When making their investing decisions, subjects of this type place relatively little weight on whether it is rational to invest, and also are less guided by whether they have invested before. We find that the Dogmatic subjects have the highest base rate of investing among all three types.

We now investigate how the institutional characteristics in our various treatments affect the type of behavioral rules subjects use. Table 6 reports the frequency of types by treatment. 
Table 6. Number of Individuals in each Treatment and each Type

According to Investing Decisions

\begin{tabular}{|c|c|c|c|c|c|}
\hline & $\begin{array}{c}\text { Seq_B } \\
12.6 \% \text { of star }\end{array}$ & $\begin{array}{c}\text { Seq_L } \\
53.5 \% \text { of star }\end{array}$ & $\begin{array}{c}\text { Sim_B } \\
12.7 \% \text { of star }\end{array}$ & $\begin{array}{c}\text { Sim_L } \\
65.3 \% \text { of star }\end{array}$ & $\begin{array}{c}\text { Sim_L_NoRFR } \\
32.4 \% \text { of star }\end{array}$ \\
\hline $\begin{array}{c}\text { "Rational" } \\
\text { Round }\end{array}$ & 9 & 23 & 0 & 3 & 22 \\
& $(31.03)$ & $(92.00)$ & $(0.00)$ & $(11.11)$ & $(70.97)$ \\
\hline "Habit" & 8 & 2 & 3 & 24 & 9 \\
Triangle & $(27.59)$ & $(8.00)$ & $(10.00)$ & $(88.89)$ & $(29.03)$ \\
\hline "Dogmatic" & 12 & 0 & 27 & 0 & 0 \\
Square & $(41.38)$ & $(0.00)$ & $(90.00)$ & $(0.00)$ & $(0.00)$ \\
\hline Total & 29 & 25 & 30 & 27 & 31 \\
& $(100.00)$ & $(100.00)$ & $(100.00)$ & $(100.00)$ & $(100.00)$ \\
\hline
\end{tabular}

Note: percentage in parenthesis

As noted above, star networks emerge in fewer than $13 \%$ of our two baseline treatments (Seq_B and Sim_B). This low level of star network formation coincides with a concentration of Dogmatic type subjects (41.38\% and 90\% respectively). That is to say, having a concentration of players using the Dogmatic investing rule is not conducive to star network formation.

On the contrary, for the Seq_L treatment, which generates a relatively high percentage of star networks, the large majority of subjects (92\%) choose to behave rationally. The other highly effective treatment, Sim_L, generates $65.3 \%$ of star networks. Its success at generating star network coincides with a high level of Habit typed subjects $(88.89 \%)$, a few Rational subjects $(11.11 \%)$ and no Dogmatic subjects.

The Sim_L_NoRFR treatment generates a medium level of star networks (32.4\%). No subject in this treatment belongs to the Dogmatic type. In particular, most of them (70.97\%) follow rational behavioral rules.

\section{b) Linking decisions}

Similar to the above analysis, the three panels of Figure 9 project each 3-vector estimate $\left\{\gamma_{1}, \gamma_{2}, \gamma_{3}\right\}$ from regression on linking decisions (Equation 8) into corresponding 2-space.

Again, we find clear visual separation between our clusters from estimates on linking behavior, and Mann-Whitney tests support significant differences between all pairs of clusters on all three axes $(p<0.001)$, again with the exception of the estimates of the constants between the 
round and triangle clusters $(\mathrm{p}=0.5279)$ (this is apparent from visual inspection of Panels $\mathrm{a}$ and $\mathrm{b}$ in Figure 9).

Interestingly, the location of the clusters closely resembles those found for investing decisions. Consequently, we assign the same labels, Rational, Habit and Dogmatic, for each of these clusters as well. Table 7 reports the mean of each estimate for each cluster and the Wilcoxon signed-rank p-value for the test of whether the cluster's mean is significantly different from zero.

Figure 9. Projections of Estimates from Linking Decision

(a)

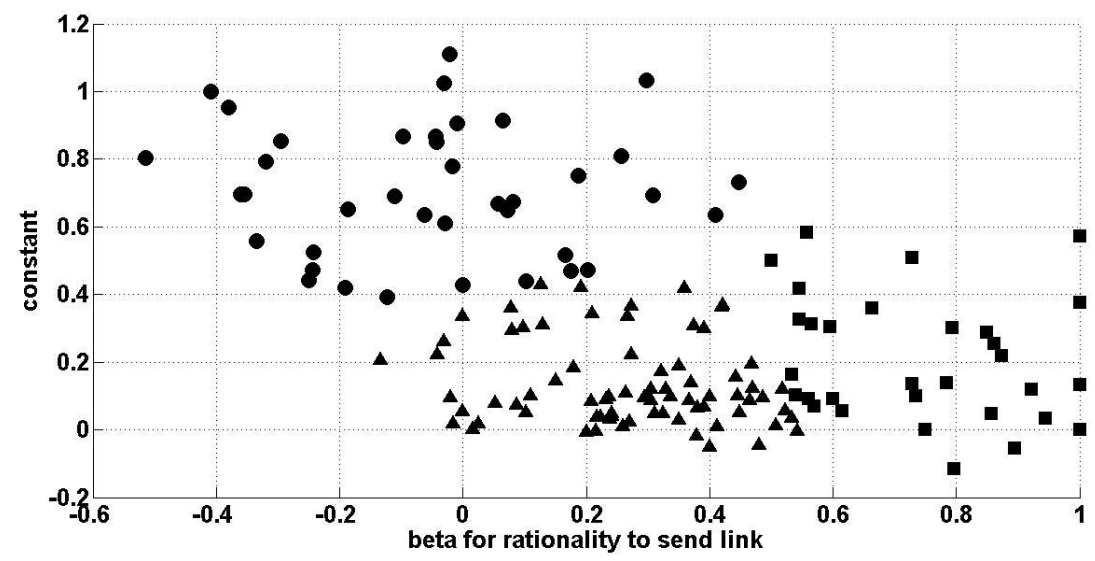

(b)

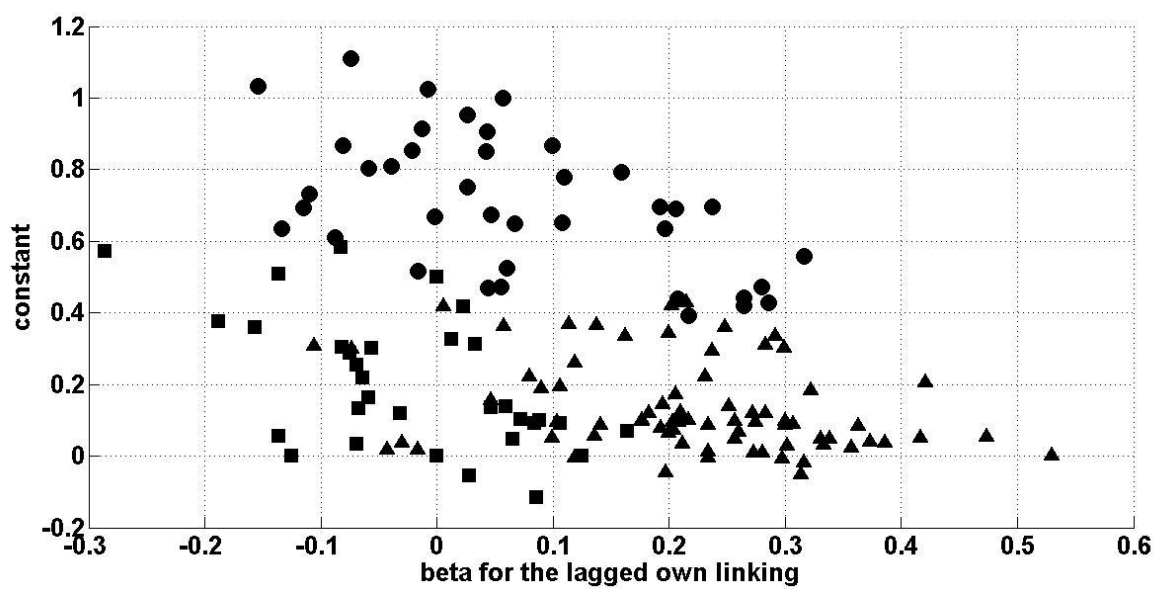


(c)

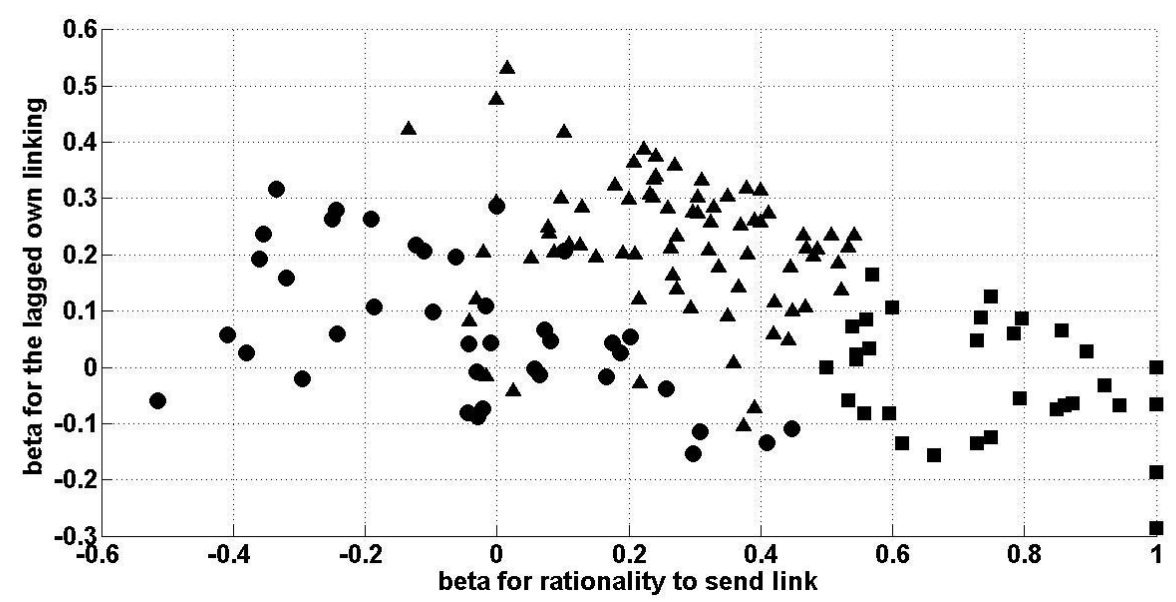

Table 7. The Mean of Estimates from Regression Analysis of Linking Behavior

\begin{tabular}{|l|l|l|l|}
\hline & Round cluster & Triangle cluster & Square cluster \\
\hline Rationality & 0.7746 & 0.2693 & -0.0461 \\
& $(0.0000)$ & $(0.0000)$ & $(0.2112)$ \\
\hline Lagged choice & -0.0187 & 0.2179 & 0.0745 \\
& $(0.4091)$ & $(0.0000)$ & $(0.0041)$ \\
\hline Base rate(constant) & 0.1735 & 0.1331 & 0.6980 \\
& $(0.0000)$ & $(0.0000)$ & $(0.0000)$ \\
\hline Number of subjects & 37 & 75 & 40 \\
\hline
\end{tabular}

Note: $p$-value from Mann-Whitney test in parenthesis

Based on the characteristics of the three clusters described in Table 7, we define three behavioral rule types as follows:

(1)We define the round cluster to be a "Rational" type. People who belong to this cluster make decisions that are guided largely by the rationality of their current choice. They have a significantly positive (but small) base rate of linking, but they do not take account of their past choices when making their decisions.

(2)We define the triangle cluster as a "Habit" type. People in this cluster make choices that resemble their previous choices. It turns out that rationality is also statistically significant, but the coefficient is smaller than that of the Rational type. 
(3) We define the square cluster as a "Dogmatic" type. Subjects in this group sent links to others at a high base rate; rationality is not a statistically significant predictor of choices for this type and while previous choices have a statistically significant coefficient that is small in magnitude. The base rate of linking is $69.8 \%$ ( statistically significantly higher than either of the other types $(\mathrm{p}<0.001))$.

To see how institutions interact with types, we report types by treatment in Table 8 .

Table 8. Number of Individuals in Different Treatments and Types According to Linking Decisions

\begin{tabular}{|c|c|c|c|c|c|}
\hline & $\begin{array}{c}\text { Seq_B } \\
12.6 \% \text { of star }\end{array}$ & $\begin{array}{c}\text { Seq_L } \\
53.5 \% \text { of star }\end{array}$ & $\begin{array}{c}\text { Sim_B } \\
12.7 \% \text { of star }\end{array}$ & $\begin{array}{c}\text { Sim_L } \\
65.3 \% \text { of star }\end{array}$ & $\begin{array}{c}\text { Sim_L_NoRFR } \\
32.4 \% \text { of star }\end{array}$ \\
\hline $\begin{array}{c}\text { "Rational" } \\
\text { round }\end{array}$ & 13 & 20 & 0 & 2 & 2 \\
\hline "Habit" & 6 & $(71.43)$ & $(0.00)$ & $(6.67)$ & $(6.25)$ \\
Triangle & $(18.75)$ & $(14.29)$ & $(40.00)$ & 24 & 29 \\
\hline "Dogmatic" & 13 & 4 & 18 & 4 & $(80.00)$ \\
square & $(40.63)$ & $(14.29)$ & $(60.00)$ & $(13.33)$ & $(3.13)$ \\
\hline Total & 32 & 28 & 30 & 30 & 32 \\
& $(100.00)$ & $(100.00)$ & $(100.00)$ & $(100.00)$ & $(100.00)$ \\
\hline
\end{tabular}

Note: percentage in parenthesis

We were surprised that the clusters found in the linking analysis resemble so closely the clusters found in our analysis of investing behaviors. In both cases, the two baseline treatments with the lowest frequency of star networks also have the highest percentage of subjects belonging to Dogmatic type ( $40.63 \%$ and $60 \%$ for Seq_B and Sim_B respectively).

Result from Seq_L shows that the majority of subjects are the Rational type. And while Sim_L has the most frequent star network formation, it also has a high percentage of Habit type subjects.

To investigate the relationship between the behavioral rules players use when making linking or investing decisions, Figure 10 plots the percentage of players belonging to each type in linking decisions conditional on each type in investing decisions ${ }^{42} .78 \%$ of subjects that are the

\footnotetext{
${ }^{42}$ Note that by construction, players in the investment-limits treatments who make rational investing decisions also necessarily make rational linking decisions. This is true only for the players who behave perfectly rationally in the
} 
Habit type in investing decisions are also Habit type in linking decisions. Similarly, there is substantial overlap among participants classified as Rational and Dogmatic between linking and investing decisions. Indeed, a Pearson Chi-square test rejects that type classifications are independent between investing and linking decisions $(\mathrm{p}<0.001)$.

Figure 10. Frequency of Each Type in Investing Decision

Conditional on Types in Linking Decision

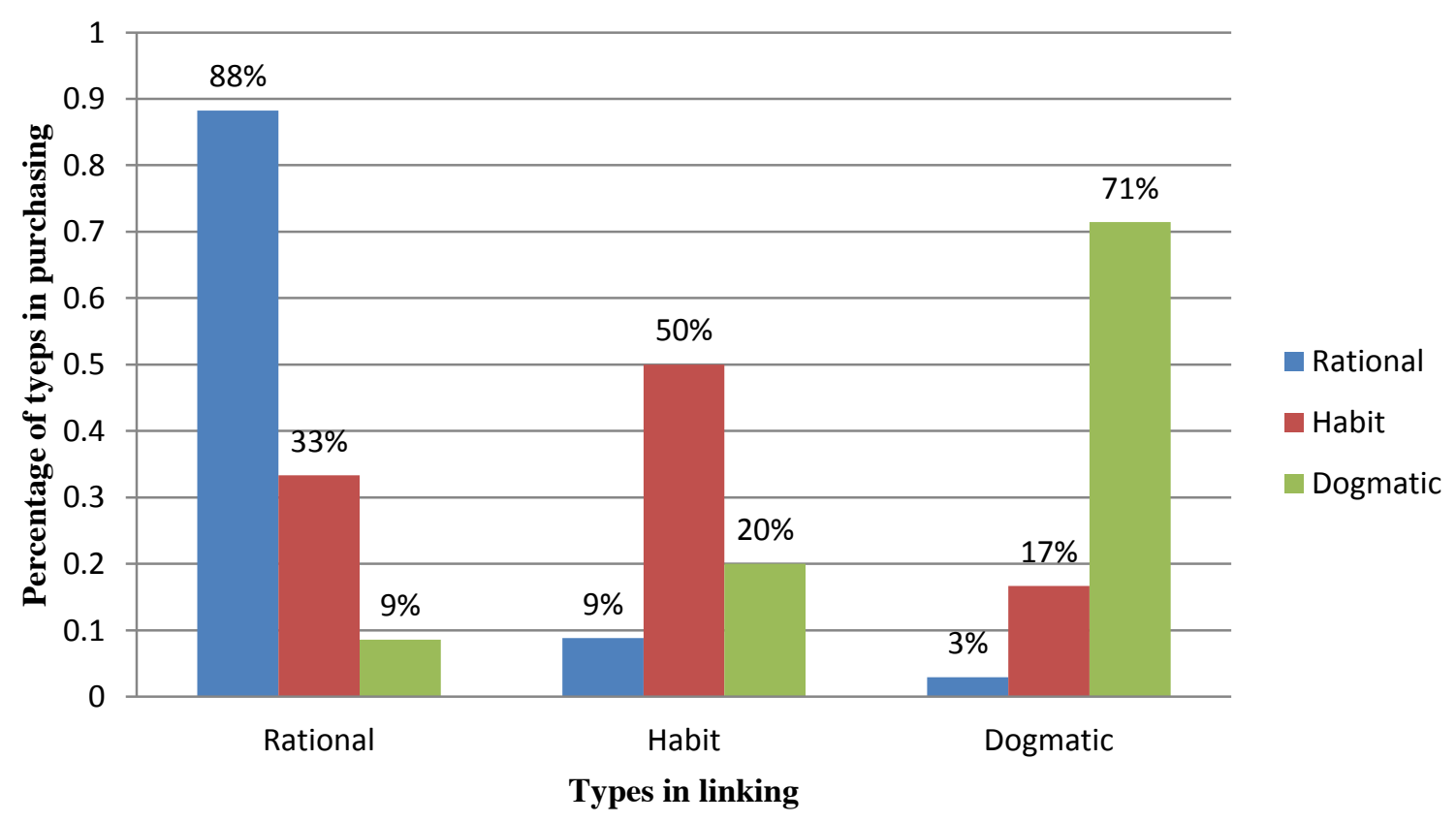

\section{VI.3. Discussion}

Our results suggest that efficient star networks are promoted by the "right" institutions, in particular, the investment limits and the right of first refusal. Both of these institutions were shown to add "stability", in a precise sense discussed in section IV.2, to the network decision environment.

As discussed in section IV.3.1, our network games with and without investment limits are theoretically equivalent, despite the fact that these limits reduce numbers of actions players can take. A possible advantage to this is that when fewer options are presented, people tend to make 
a better choice (Schwartz, 2004) ${ }^{43}$. While we do not have data to address the source of this effect, what is clear is that investment limits add substantial stability to the decision environment. This enables more sophisticated strategies to emerge under investment limits, in particular rationality and habit formation.

Similarly, we found intriguing the large and positive effect on star network emergence connected to the right of first refusal, because this institution does not alter stage game equilibrium predictions. Its main effect is to stabilize changes in players' beliefs over rounds. It is plausible that the substantial effect of RFR is due primarily to the way it promotes a stable environment.

While investment limits and the right of first refusal both facilitate star network formation, sequential decisions were much less successful. We were surprised by this latter result. Indeed, many studies have documented that sequential moves improve coordination and promote efficiency (Cooper et al, 1993; Rapoport, 1997; Guth et al, 1998; Weber et al, 2004). Depending on how it is measured, we find stability either to increase or decrease under sequential institutions, in relation to simultaneous move environments. Moreover, it does not seem that the opportunity to move sequentially improves the behavioral rules used by our participants.

It is worthwhile to note that Falk and Kosfeld (2003) and Georee et al (2006) discovered the importance of inequality aversion in preventing star networks from forming under standard theoretical conditions. This suggests that finding approaches to subsidizing investors might promote star network formation. Inequality is a feature of our environment, in that investors earn less per round than linkers, yet stars form in our environment absent subsidies ${ }^{44}$. A reason, we argue, is that when institutions enhance decision stability players are better able to rotate their network position and thus maintain a high level of overall network efficiency while concurrently equalize earnings.

It seems clear that focal points can improve coordination and promote the emergence of star networks. Goeree et al (2009) may have in part provided such a focal point by assigning common knowledge heterogeneous payoff functions. Our study shows that exogenous focal points are not necessary to grow star networks. This finding could be of value especially when

\footnotetext{
${ }^{43}$ This effect may be due to reduced cognitive load or due to the urge to optimize under the stress of a budget constraint.

${ }^{44}$ The standard deviations of payoff in Seq_L, Sim_LL and Sim_L_NoRFR are 7.05, 7.12 and 7.02, respectively. They are significantly lower at 1\% level pairwisely compare to the ones in Seq_B and Sim_B (10.48 and 9.05 respectively).
} 
policy makers intend to use focal points as coordination devices, but are either unwilling or unable to assign a focal point to a specific person. Our results suggest the possibility of designing institutions under which focal points endogenously emerge. This may be a promising approach to solving coordination problems in a wide variety of market and non-market environments.

\section{Conclusion}

Star networks emerge naturally in many social environments, and theory indicates star network equilibria are efficient. Based on a model suggested by Galeotti and Goyal (2010), we study star network formation using laboratory experiments. Previous studies indicate that persistent star networks emerge in the lab, but only under ex ante agent heterogeneity (Goeree et al, 2009). This contrasts with natural environments, where star networks frequently emerge even when agents are ex ante homogeneous (Feick and Price, 1987; Conley and Udry, 2010). We conjectured that certain stability enhancing institutions, such as sequential decisions, investment limits, and the "right of first refusal," may help to explain why star networks form in relevant natural environments.

Our main finding is that investment limits and the "right of first refusal" promote star network formation. In comparison to baseline treatments, we find that environments with those features realize increased star-network frequency, improved network stability and higher rates of individually rational choices.

In order to shed light on the impact of institutions at the individual level, we use a cluster analysis to draw inferences about behavioral rules used by participants in different environments. We find players clearly separate into using "Rational", "Habit" and "Dogmatic" rules. Moreover, "Rational" and "Habit" rules are used in the presence of institutions that promote star networks. Further, we typed each participant separately according to their linking and investment decisions. We were comforted in finding that type-classifications between these two decision domains were tightly correlated, arguing for the validity of this behavioral characterization.

To our knowledge, our paper reports the first experimental investigation of the impact of institutions on star network formation. Results from this study suggest how one might design mechanisms to promote the efficient flow of information through social networks. Our results 
should be of interest to those involved in activities including political campaigns, franchise training or agricultural innovation ${ }^{45}$.

\footnotetext{
${ }^{45}$ For example, our study suggests that when an important agricultural innovation occurs, designing a network formation process that incorporates investment limits or the RFR may lead to more knowledge transmission, therefore higher adoption rate, with lower cost.
} 


\section{References}

Bala, V. and S. Goyal (2000): “A noncooperative model of network formation”, Econometrica, 68(5) 1181-1229

Barabasi, A. and R. Albert (1999): Emergence of Scaling in Random Networks, Science, 286 (5439), 509-512.

Berninghaus, Siegfried K., K. Ehrhart and M. Ott (2006): A network experiment in continuous time: The influence of link costs, Experimental Economics, 9:237-251

Berninghaus, Siegfried K., K. Ehrhart, M. Ott and B. Vogt (2007): Evolution of networks - an experimental analysis, Journal of Evolutionary Economics, 17: 317-347

Berninghaus, S.K.; Ehrhart, K.-M.; Ott, M. (2011): Forward-Looking Behavior in Hawk-Dove Games in Endogenous Networks: Experimental Evidence, Games and Economic Behavior, 75: $35-52$

Bramoulle, Y. \& R. Kranton (2007): Public goods in networks, Journal of Economic Theory,135(1) 478-494

Bramoulle, Y., D. Lopez-Pintado, S. Goyal and F. Vega-Redondo (2004): Network Formation and Anti-coordination Games, International Journal of Game Theory, 33 1-19

Callander, S., and C. Plott (2005): Principles of Network Development and Evolution:

An Experimental Study, Study of Public Economics 89:14691495

Calinski, T. and Harabasz, J. (1974): A dendrite method for cluster analysis, Communications in Statistics 3, 1-27

Conley, T. and C. Udry (2010): Learning about a New Technology: Pineapple in Ghana, American Economic Review,100(1) 35-69 
Cooper, R., Dejong, D., Forsythe, R. and Ross,T. (1993): Forward Induction in the Battle-ofthe_Sexes Games, American Economic Review, 83,1303-1316

Corbae, D. \& J. Duffy (2008): Experiments with network formation, Games and Economic Behavior, Elsevier, 64(1) 81-120

Deck, C. and C. Johnson (2004): Link bidding in a laboratory network.. Review of Economic Design, 8 (4): 359-372.

Dodd, P., J. Watts and F. Sabel (2003): "Information exchange and the robustness of organizational networks", Proceedings of National Academy of Science USA, 100 12516-12521

DiMasi, J., R. Hansen and H. Grabowski (2003): The price of innovation: new estimates of drug development costs, Journal of Health Economics, 22 151-185

DiMasi, J and H. Grabowski (2007): The Cost of Biopharmaceutical R\&D: Is Biotech Different? Managerial and Decision Economics, 28: 469-479

Droste, E., R. Gilles and K. Johnson (2000): Endogenous interaction and the evolution of conventions, working paper

Duda, R and P. Hart (1973): Pattern classification and scene analysis, Wiley, New York

Everitt, B, S. Landau, M. Leese and D. Stahl (2011): Cluster Analysis, Wiley Press, 5th edition

Falk, A., and M. Kosfeld (2003): It's All About Connections: Evidence on Network Formation, Institute for the Study of Labor (IZA) Discussion Paper 777, Zurich IEER

Feick, L and L. Price (1987): The Market Maven: A Diffuser of Marketplace Information, Journal of Marketing, 51(1) 83-97 
Fisher, W (1698): Clustering and Aggregation in Economics, The Johns Hopkins University Press

Fischbacher, U. (2007): z-Tree: Zurich Toolbox for Ready-made Economic Experiments, Experimental Economics, 10(2) 171-178

Foster, A. and M. Rosenzweig (1995): Learning by Doing and Learning from Others: Human Capital and Technical Change in Agriculture, Journal of Political Economy, 103(6) 1176-1209,

Gladwell, M (2000): The Tipping Point: How Little Things Can Make a Big Difference, Little Brown

Galeotti A., S. Goyal and J. Kamphorst (2006): Network Formation with Heterogenous Players, Games and Economic Behavior, 54(2), 335-372

Galeotti, A. and S. Goyal (2007): The law of the few, Working paper version

Galeotti, A. and S. Goyal (2010): The law of the few, American Economic Review, 100(4) 1468-92.

Geissler G. and S. Edison (2005): Market Mavens' Attitudes Towards General Technology: Implications for Marketing Communications, Journal of Marketing Communications, 11, 2, 7394.

Godes, D. and M. Dina (2009): Firm-Created Word-of-Mouth Communication: Evidence from a Field Study, Marketing Science, 28 (4), 721-739.

Goeree, J., A. Riedl and A. Ule (2009): "In search of stars: Network formation among heterogeneous agents", Games and Economic Behavior, 67(2) 445-466

Goyal, S. and F. Vega-Redondo (2005): Network Formation and Social Coordination, Games 
and Economic Behavior, 50 178-207

Guth, W., Huck, S. and Rapoport, A.(1998): The Limits of the Positional Order Effect: Can it Support Silent Threats and Non-Equilibrium Behavior, Journal of Economic Behavior and Organization, 34(2) 313-325

Hansen, P. and B. Jaumard (1987): Minimum sum of diameters clustering, Journal of Classfication, 4 215-226.

Hartigan, J. A. and Wong, M. A. (1979). A K-means clustering algorithm. Applied Statistics, 28, 100-108.

Hirschberg, J., E. Maasoumi and D. Slottje (1991): Cluster analysis for measuring welfare and quality of life across countries, Journal of econometrics, 50(1-2) 131-150

Houser, D and M. Keane and K. McCabe (2004): Behavior in a dynamic decision problem: An analysis of experimental evidence using a Bayesian type classification algorithm, Econometrica,72:3, 781-822.

Iyengar, R., Van Den Bulte, C., \& Valente, T. W. (2010): Opinion Leadership and Social Contagion in New Product Diffusion, Marketing Science, 30(2), 195-212.

Jackson, M. and B. W. Rogers (2007): Meeting Strangers and Friends of Friends: How Random Are Social Networks?, American Economic Review, 97(3), 890-915

Jackson, M and A. Watts (2002): On the Formation of Interaction Networks in Social Coordination Games, Games and Economic Behavior, 41 265-291

Jackson, M. and A. Wolinsky(1996): A Strategic Model of Social and Economic Networks, journal of economic theory, 71 44-74 
Jackson, M. an D. Lopez-Pintado (2011): Diffusion in Networks with Heterogeneous Agents and Homophily', working paper

Jackson, M. (2003): A survey of models of network formation: Stability and efficiency, Game Theory and Information 0303011, EconWPA.

Jackson, M. (2009): An Overview of Social Networks and Economic, Handbook of Social Economics Applications

Jajuga, K., M. Walesiak and A. Bak (2003): On the general distance measure, in Exploratory Data Analysis in Empirical Research, Springer-Verlag, Heidelberg. , 104-109.

Kaufman, L. and P. Rousseeuw (1990): Finding Groups in Data: An Introduction to Cluster Analysis. Wiley, New York

Katz, E. and P. Lazarsfeld (1955): Personal Influence; the Part Played by People in the Flow of Mass Communications, Free Press.

Kelly, J., et al. (1992): Community AIDS/HIV risk reduction: The effects of endorsements by popular people in three cities. American Journal of Public Health, 82, 1483-1489.

Knigge, A. and V. Buskens (2010): Coordination and Cooperation Problems in Network Good Production, Games, 1(4): 357-380.

Köhn HF, D. Steinley and M. Brusco (2010): The p-median model as a tool for clustering psychological data, Psychologic Methods.15(1):87-95.

Kurzban, R and D. Houser (2005): Experiments investigating cooperative types in human groups: A complement to evolutionary theory and simulations, Proceedings of the National Academy of Sciences of the United States of America, 102(5), 1803-1807. 
Larrosa, J and F. Tohm (2011): Network Formation with Heterogeneous Agents, working paper Liu, G. (1968): Introduction to combinatorial mathematics, McGraw Hill

Marsden, P. and K. Campbell (1984): Measuring Tie Strength, Social Forces, 63 (2): 482-501

Merton, Robert K (1968), Social Theory and Social Structure. New York: Free Press.

Milligan, G. and M. Cooper (1985): An examination of procedures for determining the number of clusters in a data set. Psychometrika, 159-159

Rand, W. M. (1971): Objective criteria for the evaluation of clustering methods, Journal of the American Statistical Association, 66 (336): 846-850

Rapoport, A (1997): Order of Play in Strategic Equivalent Games in Extensive Form, Internaltional Journal of Game Theory, 26(1) 113-136

Roch, C. H. (2005): The Dual Roots of Opinion Leadership, Journal of Politics, 67, 110-31.

Rogers, E. (2003): Diffusion of Innovation, Free Press, 5th edition

Schwartz, B., The paradox of choice: Why less is more, New York: Ecco, 2004

Song, L.,S. Appleton and J. Knight (2006): Why do girls in rural China have lower school enrollment? World Development. 34(9), 1639-1653

Steinley, D (1006b): K-means clustering: A half-century synthesis, British Journal of Mathematical and Statistical Psychology, 59(1)

Tran, A. (2009): Can Procurement Auctions Reduce Corruption? Evidence from the Internal Records of a Bribe-Paying Firm, working paper

Ule, Aljaz (2008): Partner Choice and Cooperation in Networks: Theory and Experimental 
Evidence, Springer Verlag

Valente T. (1995): Network Models of the Diffusion of Innovations, Hampton Press

Vandenbossche, J. and T. Demuynck (2010): Network formation with heterogeneous agents and absolute friction, Working Papers

Weber, R., C. Camerer and M. Knez (2004): Timing and Virtual Observability in Ultimatum Bargaining and "Weak Link" Coordination Games, Experimental Economics, 7:25-48

Weimann, G. (1994): The influentials: The people who influence people. New York: State University of New York Press.

Wiedmann K.P., G. Walsh and V.W. Mitchell (2001): The Mannmaven: an agent for diffusing market information, Journal of Marketing Communications, 7, 185-212.

Williams, T.G. and M.E. Slama (1995): Market mavens' purchase decision evaluative criteria: implications for brand and store promotion efforts, Journal of Consumer Marketing, 12, 3, 4-21. 


\section{Appendix A. Z-tree experimental interface}

Fig.A An example of the decision screen

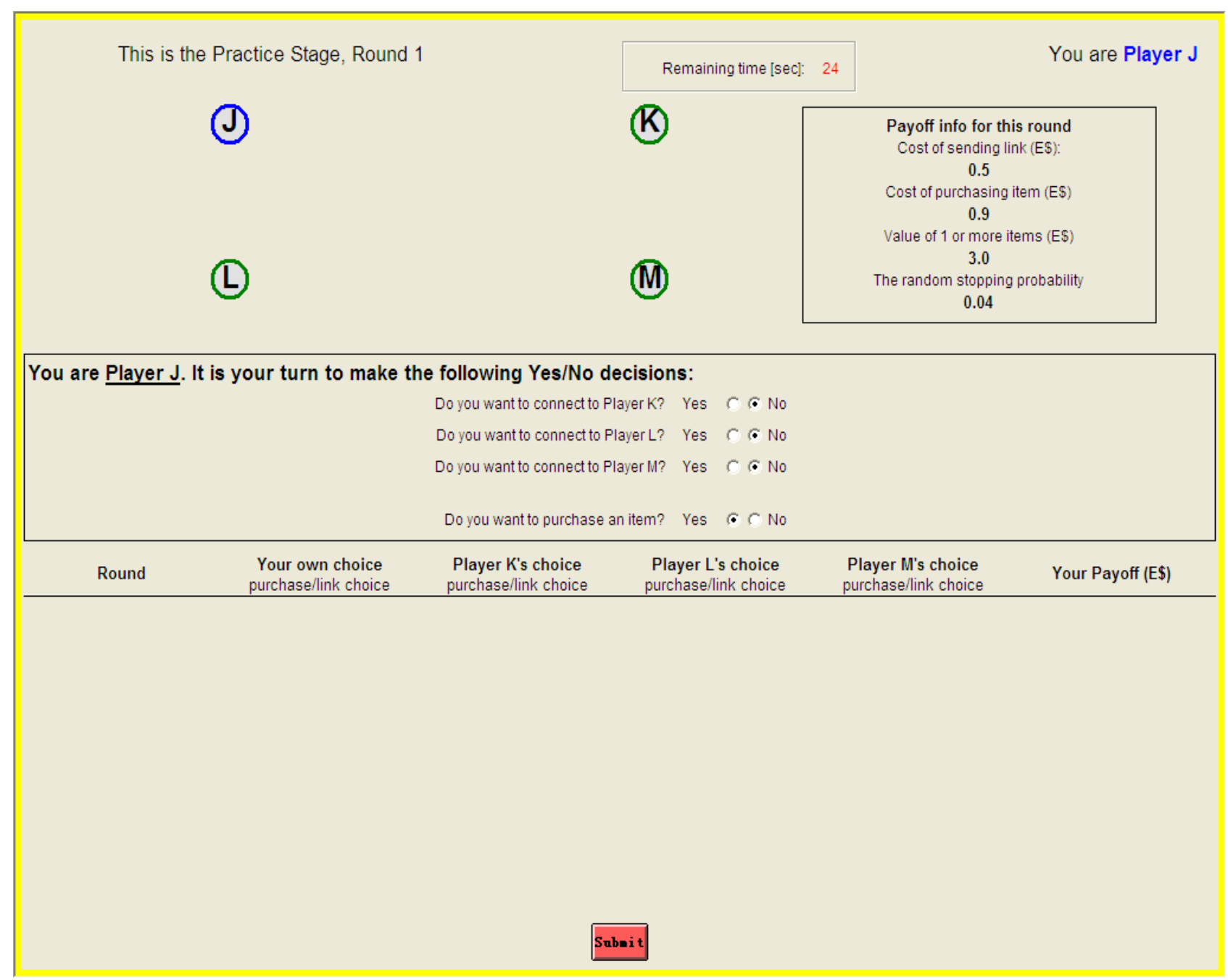




\section{Appendix A, continue}

Fig B. An example of the display screen

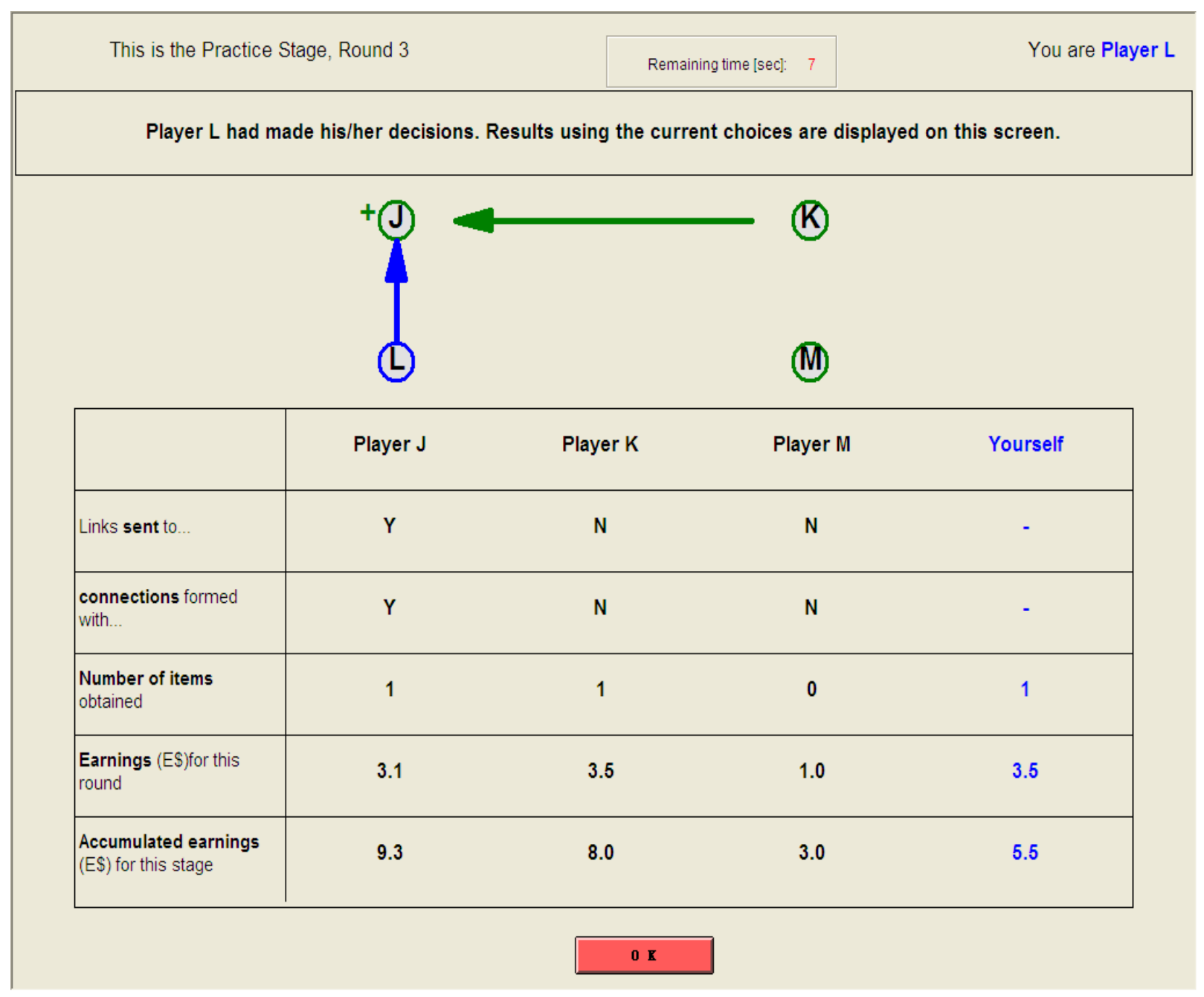




\section{Appendix B. Multiple Comparison Correction:}

We find most of the results in section IV.1 hold when we correct the p-value for multiple comparisons. Table A-D report pair-wise comparisons between treatments with a Bonferroni correction for equilibrium frequency, equilibrium duration, disequilibrium duration and individual rationality. Table entries show row mean-column mean ( $\mathrm{p}$-value in parenthesis).

Table A. Differences in the mean frequency of star networks by treatments

\begin{tabular}{|l|l|l|l|l|}
\hline & Seq_B & Seq_L & Sim_B & Sim_L \\
\hline Seq_L & 0.4078 & & & \\
& $(0.000)$ & & & \\
\hline Sim_B & -0.0011 & -0.4089 & & \\
& $(1.000)$ & $(0.000)$ & & \\
\hline Sim_L & 0.5260 & 0.1182 & 0.5271 & \\
& $(0.000)$ & $(1.000)$ & $0.000)$ & \\
\hline Sim_L_noRFR & 0.1963 & -0.2115 & 0.1974 & -0.3297 \\
& $(0.080)$ & $(0.044)$ & $(0.076)$ & $(0.000)$ \\
\hline
\end{tabular}

Table B. Difference of the mean equilibrium duration by treatments

\begin{tabular}{|l|l|l|l|l|}
\hline & Seq_B & Seq_L & Sim_B & Sim_L \\
\hline Seq_L & 0.223 & & & \\
& $(0.022)$ & & & \\
\hline Sim_B & 0.052 & -0.217 & & \\
& $(1.000)$ & $(0.028)$ & & \\
\hline Sim_L & 0.369 & 0.147 & 0.364 & \\
& $(0.000)$ & $(0.409)$ & $0.000)$ & \\
\hline Sim_L_NoRFR & 0.132 & -0.091 & 0.126 & -0.238 \\
& $(0.664)$ & $(1.000)$ & $(0.778)$ & $(0.011)$ \\
\hline
\end{tabular}

Table C. Difference of the mean disequilibrium duration by treatments

\begin{tabular}{|l|l|l|l|l|}
\hline & Seq B & Seq L & Sim B & Sim L \\
\hline Seq_L & -0.361 & & & \\
& $(0.001)$ & & & \\
\hline Sim_B & 0.058 & 0.419 & & \\
& $(1.000)$ & $(0.000)$ & & \\
\hline Sim_L & -0.416 & -0.055 & -0.474 & \\
& $(0.000)$ & $(1.000)$ & $(0.000)$ & \\
\hline Sim_L_NoRFR & -0.253 & 0.108 & -0.310 & 0.164 \\
& $(0.048)$ & $(1.000)$ & $(0.006)$ & $(0.650)$ \\
\hline
\end{tabular}

Table D. Difference of the mean disequilibrium duration by treatments

\begin{tabular}{|l|l|l|l|l|}
\hline & Seq_B & Seq_L & Sim_B & Sim_L \\
\hline Seq_L & 0.333 & & & \\
& $(0.000)$ & & & \\
\hline Sim_B & -0.114 & -0.447 & & \\
& $(0.314)$ & $(0.000)$ & & \\
\hline Sim_L & 0.270 & -0.062 & 0.385 & \\
& $(0.000)$ & $(1.000)$ & $(0.000)$ & \\
\hline Sim_L_NoRFR & 0.069 & -0.264 & 0.183 & -0.202 \\
& $(1.000)$ & $(0.000)$ & $(0.007)$ & $(0.002)$ \\
\hline
\end{tabular}




\section{Appendix C. 3-space Plot for Individuals' Estimates by Treatment}

(a) Investing decisions

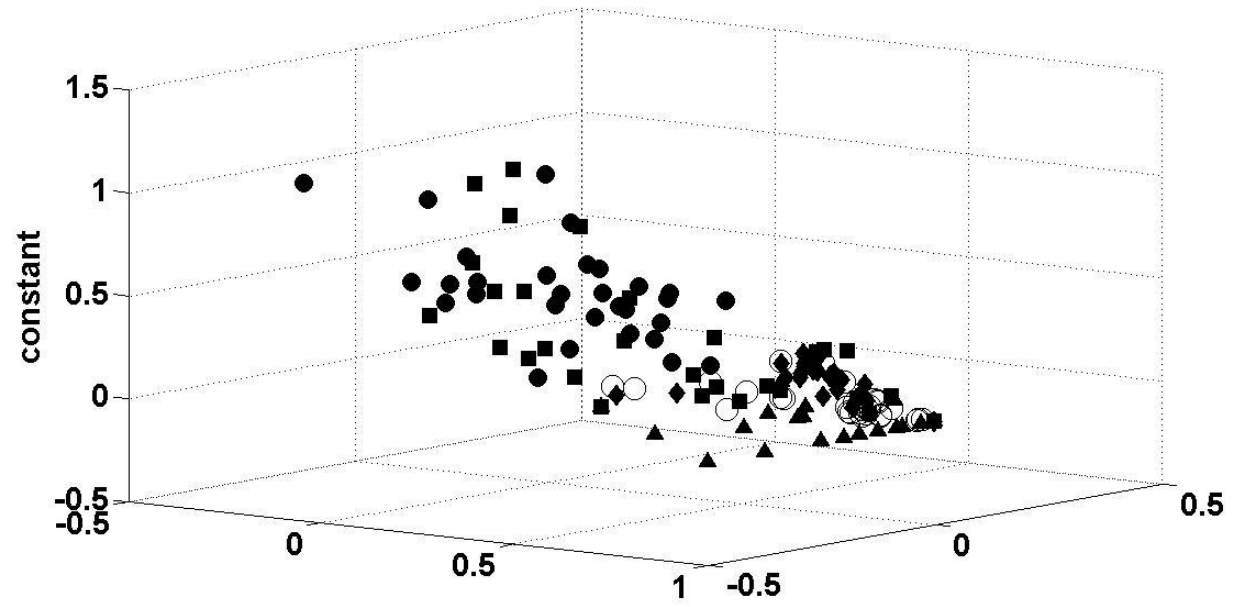

beta for rationality to purchase

beta for the lagged own purchase

(b) Linking decisions

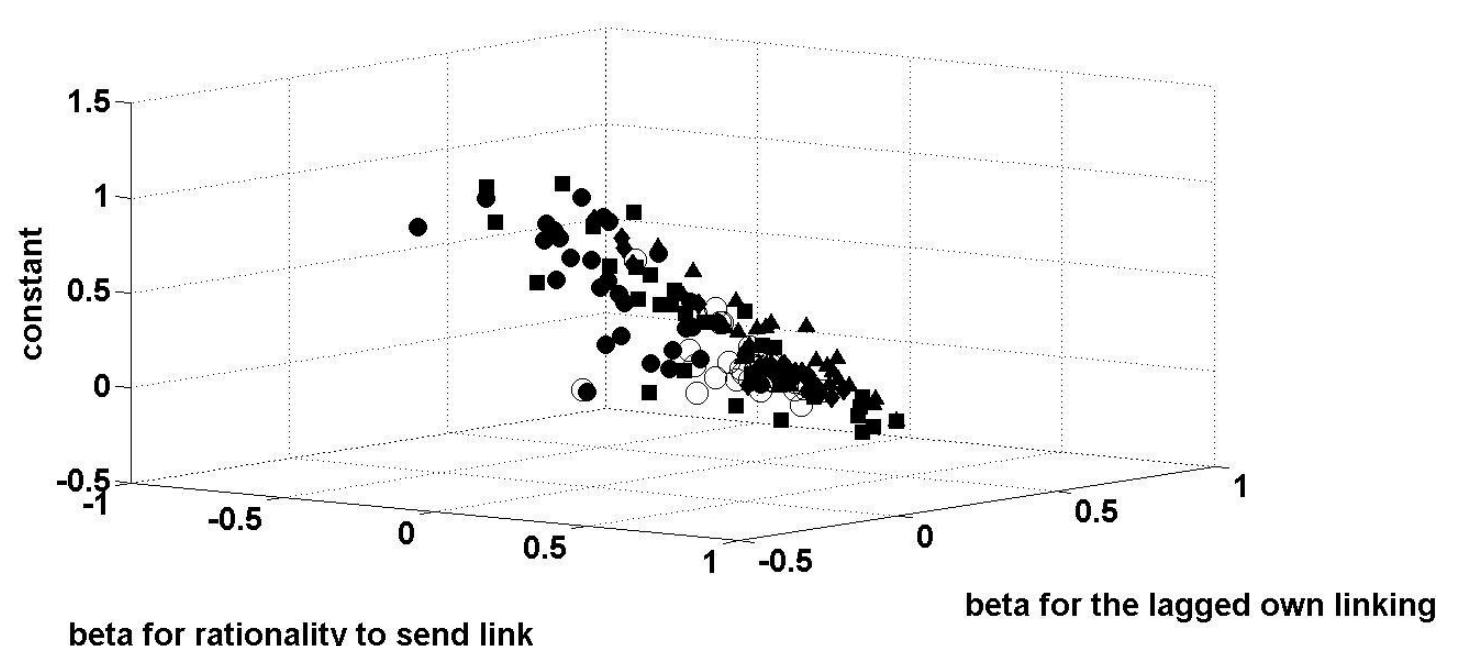

beta for rationality to send link

Note: different markers represent different treatments

口 --Seq_B ; $\Delta$--Seq_L; • --Sim_B; $\bullet-$-Sim_L; ○ -- Sim_L_NoRFR 
(a) Investing decisions

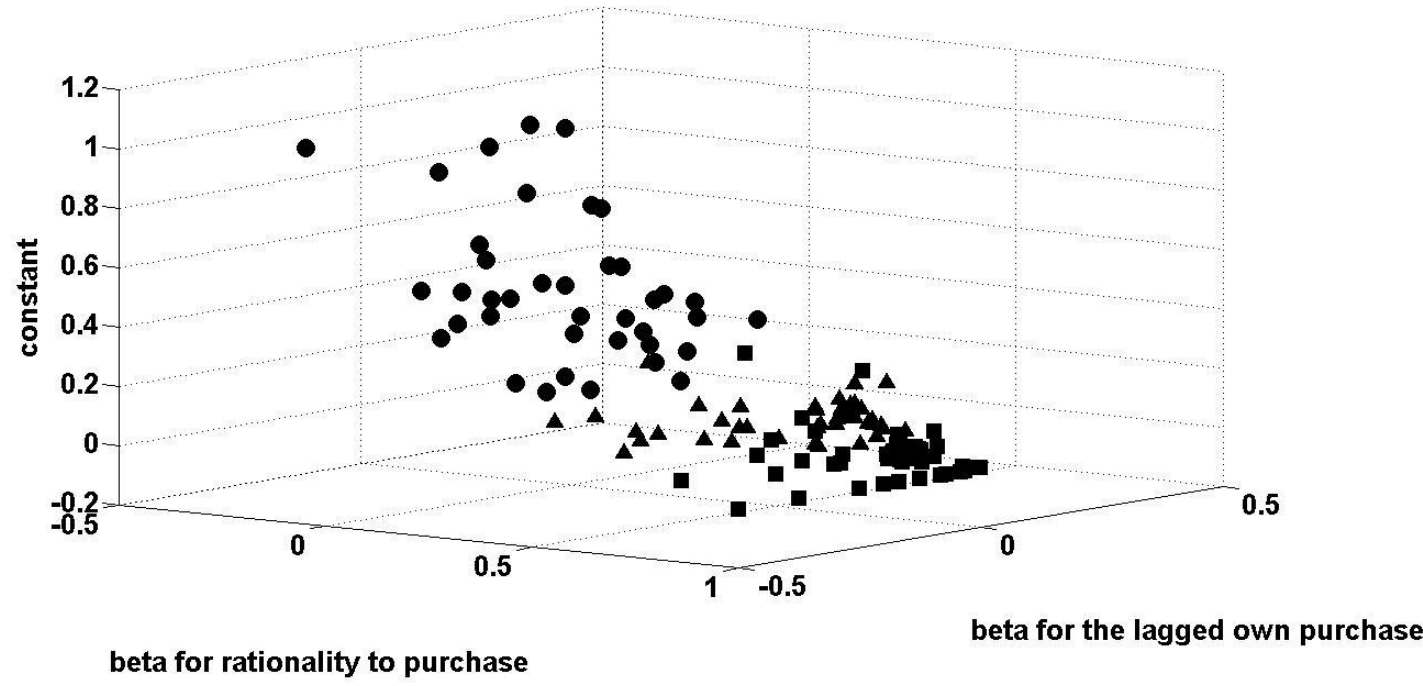

(b) Linking decisions

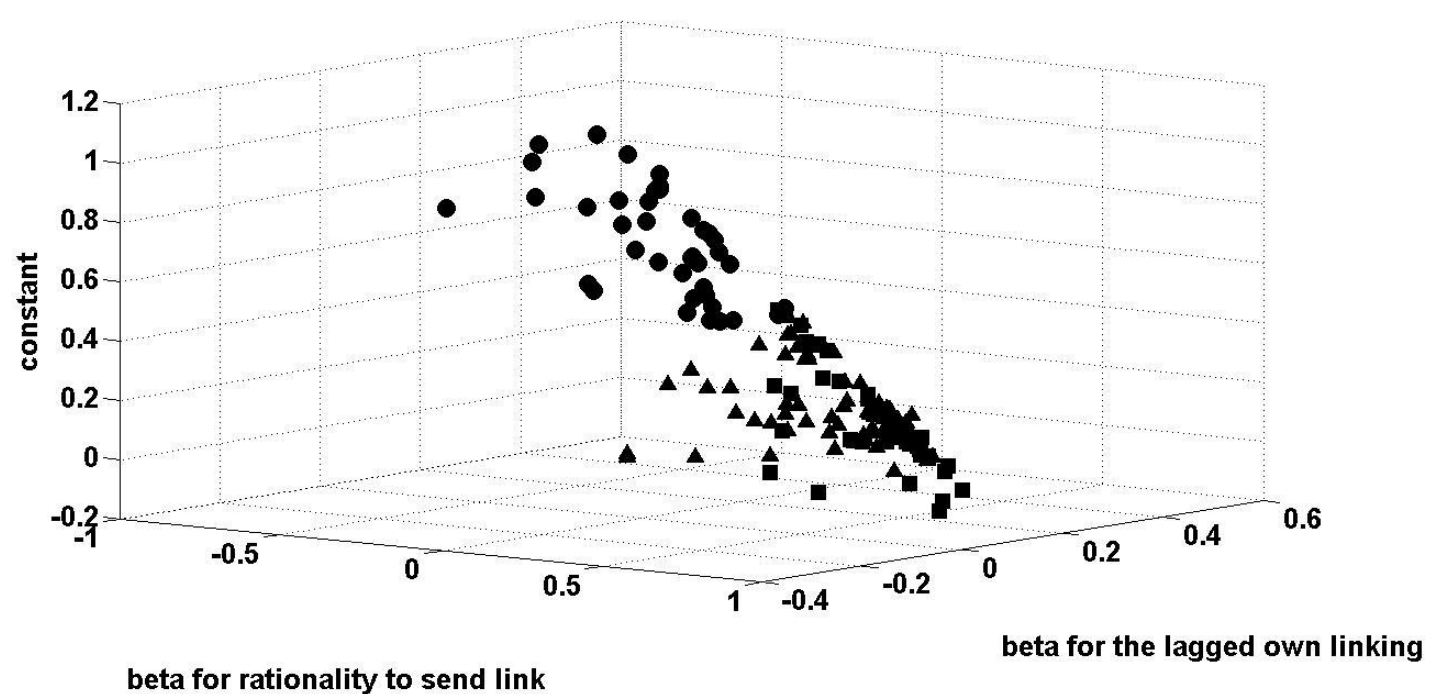

